\title{
APPLICABILITY OF THE EVIDEM MULTI-CRITERIA DECISION ANALYSIS FRAMEWORK FOR ORPHAN DRUGS - RESULTS FROM A STUDY IN 7 EURASIAN COUNTRIES
}

\author{
ALEKSANDRA BARAN-KOOIKER ${ }^{1}$, KAGAN ATIKELER $^{2,3}$, KAMILLA GAITOVA $^{4}$, \\ MALWINA HOLOWNIA-VOLOSKOVA ${ }^{5,6}$, ADINA TURCU-STIOLICA $^{7}$, \\ $\mathrm{COEN} \mathrm{KOOIKER}^{8}$, ORESTA PINIAZHKO $^{9}$ and MARCIN CZECH ${ }^{10,11 *}$
}

${ }^{1}$ Department of Pharmacoeconomics, Faculty of Pharmacy, Medical University of Warsaw, Warsaw, Poland

${ }^{2}$ Division of Pharmacoepidemiology and Clinical Pharmacology, Faculty of Science,

Utrecht Institute for Pharmaceutical Sciences, Utrecht, The Netherlands

${ }^{3}$ Ministry of Health Turkey, Turkish Medicines and Medical Devices Agency,

Unit of Health Technology Assessments, Ankara, Turkey

${ }^{4}$ Health Technology Assessment Department, Republican Center for Health Development,

Ministry of Health, Astana, Kazakhstan

${ }^{5}$ State Budgetary Institution "Clinical Trials and Healthcare Technology Assessment Centre of Moscow Department of Health", Moscow, Russia

${ }^{6}$ Department of Experimental and Clinical Pharmacology, Medical University of Warsaw, Warsaw, Poland

${ }^{7}$ Department of Pharmacoeconomics, Faculty of Pharmacy, University of Medicine and Pharmacy

of Craiova, Craiova, Romania

${ }^{8}$ Independent Researcher, The Netherlands

${ }^{9}$ Department of Management and Economy of Pharmacy, Medicine Technology and Pharmacoeconomics,

Postgraduate Faculty,

Danylo Halytsky Lviv National Medical University, Lviv, Ukraine

${ }^{10}$ Department of Pharmacoeconomics, The Institute of Mother and Child, Warsaw, Poland

${ }^{11}$ Warsaw University of Technology Business School, Warsaw, Poland

\begin{abstract}
Several Multi-Criteria Decision Analysis (MCDA) models for use in health technology assessment (HTA) have been developed over the years, including some for orphan drugs. However, there is no general consensus yet on MCDA structure and which criteria should be included and implementation of MCDA into HTA practice has been slow so far. Our study tested the criteria preferences and possibilities for implementation of the EVIDEM MCDA framework for orphan drugs with a diverse group of 140 stakeholders in Kazakhstan, Netherlands, Poland, Romania, Russia, Turkey and Ukraine (KZ, NL, PL, RO, RU, TR, UA). The research elicited stakeholder preferences (weighting) for EVIDEM domains, criteria and sub-criteria to measure their relative importance. Correlations of the workplace and HTA/rare diseases experience with weighting results were investigated. Results showed that the 'Need for intervention' domain was assessed as the most important in RO/NL/RU/TR, in KZ/PL the 'Type of benefit of intervention' and in UA 'Economic consequences of intervention'. 'Population Priorities' was uniformly given a low priority. Further research, sharing of experiences and multi-stakeholder discussion is necessary to define a path forward for a robust and sustainable improvement of MCDA models and its application in orphan drug HTA. Model simplification and clarification of outcomes would be beneficial.
\end{abstract}

Keywords: MCDA, EVIDEM, orphan drugs, rare diseases, HTA, criteria, weighting

Diseases that are life-threatening or chronically debilitating are qualified as rare diseases (RD) in the EU if their prevalence is $\leq 5$ per $10.000(1,2)$. One in 17 people in the EU ( 27 to 36 million people) suffer from one or more of the 6000-8000 rare diseases that exist $(2,3)$.
Many rare diseases are characterized by an early/juvenile onset and a fast and progressive course of the disease, which makes early access to drugs paramount to stop disease progression and prevent irreversible organ and tissue damage (4). The level of access to orphan medicinal products

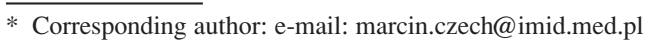


(OMPs) varies significantly in Europe, depending on factors such as healthcare and rare disease budget and length of reimbursement processes $(5,6)$. Many orphan drugs are priced far above commonly acceptable levels, which manufacturers often justify by the small disease population and their limited options for return on investment, while still having to go through a relatively expensive clinical development program (7). High prices in combination with limited evidence and evidential uncertainty (due to small and heterogeneous populations and difficulties in defining and measuring clinical endpoints), typically lead to cost-effectiveness ratios that are hard to justify by payers (7-14).

HTA agencies sometimes apply waivers and reduced data/dossier requirements for orphan drugs in some form or other (e.g. France, Turkey) or apply increased acceptable ICER levels in pharmacoeconomic assessments (e.g. for ultra-orphan drugs in the UK) (15-20). However, in many European countries, there is no tailored HTA approach towards OMPs. To address this gap, researchers are looking for a new and appropriate methodology to assess the fair value of OMPs and facilitate a predictable and unambiguous pharmacoeconomic evaluation. One of these methods is Multi-Criteria Decision Analysis (MCDA), a decision-making tool that can aggregate multidimensional factors and information into a single outcome score (21) which can be used to compare different methodologies. MCDA has been in use in a range of industries $(22,23)$ and it is starting to be deployed in HTA where it can be suitable to define a more 'holistic' value of medicinal technologies, beyond standard cost per QALY. Several

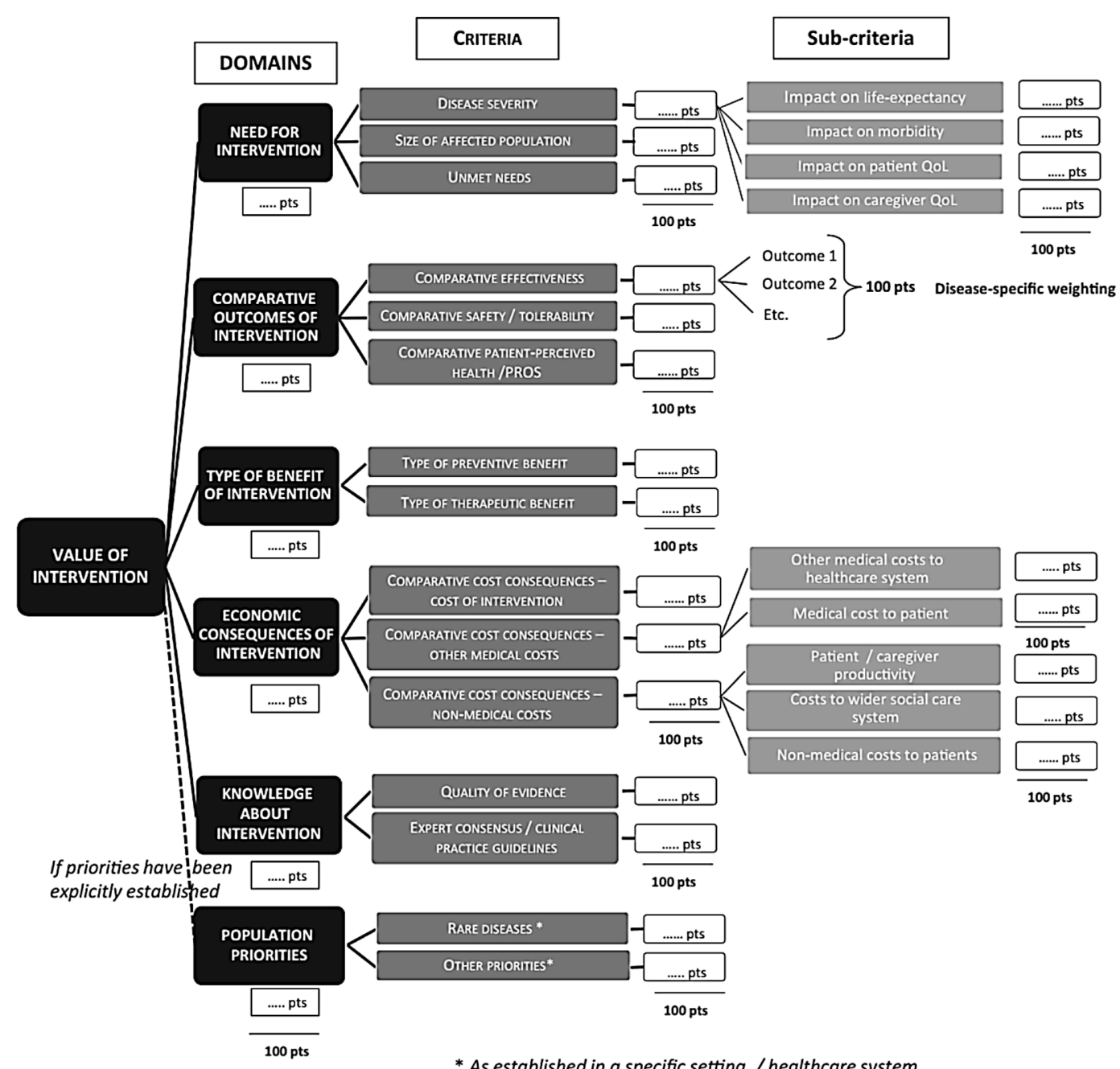

Figure 1. Adapted EVIDEM framework v3.0 created by Wagner et al. (39) 
European HTA agencies use (elements of) MCDA methodology, e.g. PASFTAC (Catalunya) $(24,25)$ and in some countries MCDA is implemented in legislation (e.g. Hungary, Lombardy) $(26,27)$.

Several authors have published articles on the use of MCDA in orphan drug HTA as a method to overcome the existing difficulties (28-32). This has resulted in several OMP MCDA model designs, of which the Transparent Value Framework (TVF) and EVIDEM framework have been tested in several countries $(33,34)$.

EVIDEM is the model that has been used the most frequently in scientific studies $(24,35,36)$. The focus of these publications has been solely Western Europe, no research has been done concerning the use and applicability of EVIDEM in Eastern European countries. The authors, a collaboration between 7 researchers from 7 countries, have decided to conduct complementary research by testing the EVIDEM framework (3.0) adapted for orphan drug appraisal in their respective home countries: Kazakhstan, Russia, Turkey and Ukraine (non-EU) and Poland, Romania and The Netherlands (EU members), as presented in Figure 1. The selected countries share certain geographical proximity but are diverse in population size, economy, healthcare system and HTA processes and therefore could represent a valid sample of the Northwestern Eurasian region.

The purpose of the study was to perform a weight elicitation for the EVIDEM rare disease model (v3.0) in a wider region in Eurasia with a sizeable group of experts (100-200), in order to identify key differences between countries and types of stakeholders as well as to compare weighting results from other studies. A secondary goal was to test the usefulness of a questionnaire tool designed for this purpose. To the best of the authors' knowledge, this is the first attempt to test the applicability of MCDA (EVIDEM v3.0) tailored for rare diseases. This research focused on eliciting stakeholder preferences for domains, criteria and sub-criteria to measure their relative importance.

\section{METHODS}

\section{The EVIDEM framework}

The EVIDEM framework (3.0) designed by Goetghebeur et al. is comprised of a broad range of criteria that enables capturing elements of drug value not only relevant for decision-makers but also to patients and society $(37,38)$. It consists of 13 quantitively measurable "core" criteria grouped into domains for which preferences can be weighted to reflect their relative importance from different stakeholder perspectives. EVIDEM also includes 7 qualitative criteria to capture contextual factors, e.g. affordability and opportunity costs, alignment with the healthcare system or alignment with 'common goals' rather than 'special interests' (The original EVIDEM model was adapted for rare diseases and orphan drugs by Wagner et al. in 2016 (39) by incorporating specific OMP/RD factors and sub-criteria. Please refer to Figure 1 for the model overview (39). The EVIDEM MCDA model calculation consists of 2 separate processes: weighting (the first step) and scoring. Weighting comprises attaching a level of importance (weight) to certain MCDA factors in order to reflect the preference of the stakeholders involved. For example, the HTA decision board in a certain country might attach a high weight to medical outcomes and low weight to disease prevalences. Weighting is done independently from any technology (no product is assessed) and is often performed by expert representatives. Scoring is done during a technology assessment, by assigning points for a certain medical intervention to the model fields (e.g. domains/criteria/sub-criteria). The aggregate MCDA value of a technology is calculated by multiplying each criterion score by the previously established criterion weight and adding these numbers to an aggregate sum $(40,41)$.

\section{Study and questionnaire design}

The EVIDEM model for rare diseases (v3.0, Wagner at al.) was used to create a questionnaire tool in MS Excel. This questionnaire tool allowed to input weights for all quantitative EVIDEM fields (domains, criteria and sub-criteria), with checksums in place to ensure total score allocation and to prevent accidental over- and underweighting. The 'contextual' normative and feasibility criteria in the EVIDEM model, which are criteria for qualitative appraisal, were not included in the questionnaire as the focus of this study was on quantitative weight elicitation.

The questionnaire and instructions were translated into 7 local languages (Dutch, Kazakh, Polish, Romanian, Russian, Turkish and Ukrainian) by professional translators. The correctness of the translations, as well as the functionality of the questionnaire, was reviewed and validated by several experts from the reimbursement/HTA field from the countries where the study was conducted. The questionnaire (incl. the tool and instructions for use) was distributed via email and filled in digitally or a live interview was held and questionnaire responses were noted on paper. Researchers from each target country informed the respondents about the purpose 
of the study and instructed them on how to fill out the questionnaire.

The respondents' main task was to assign weights based on personal preferences with the perspective of orphan drug HTA and reimbursement in mind. For this purpose a hierarchical 100-point allocation method was used, where a higher number reflects a higher relative preference/importance. One hundred points in total were to be divided over the 6 EVIDEM domains; 100 points over each of the 6 groups of criteria (in total 15 criteria, $6 \times 100$ points) and 100 points over each of the 3 groups of sub-criteria ( 9 sub-criteria in total, $3 \times 100$ points). This method was proposed and described by the authors of the adapted EVIDEM model (39). For a clear overview of all fields used in the weighting please refer to Figure 1. Basic demographic data of each respondent were recorded for analysis of possible correlations between weighting results and these respondent characteristics: country, type of company/institution, professional experience and length of experience rare disorders and in HTA/reimbursement field, if any. After completion of the questionnaire, interviewees were asked to provide general comments on the applicability and possible implementation of MCDA in orphan drug HTA in the context of EVIDEM framework v3.0.

Questionnaire completion and interviews with stakeholders took place from February to April 2018. The study has a sociological character from a methodological point of view, with no clinical research elements, therefore approval by an ethics committee was not required. All data has been anonymized for publication and no personal data was collected in this study.

\section{Study participants}

Study participants included experts in the fields of HTA and reimbursement and/or rare diseases from the selected 7 countries (Kazakhstan, Poland, Turkey, The Netherlands, Romania, Russia and Ukraine) including: doctors, pharmacists, lawyers, economists, biologists, chemists, biotechnologists and others working for governmental organizations (e.g. Ministry of Health, HTA agencies), universities, hospitals/clinics, pharmaceuti$\mathrm{cal} /$ consulting companies, as well as rare disease patients.

Despite detailed guidance on how to complete the questionnaire and a step-by-step explanation of terminology, preliminary results and discussion with rare disease patients indicated that the questionnaire was too complex and not fully comprehensible for all rare disease patients or their caregivers.
Therefore the researchers did not further conduct interviews of patients or patient representatives.

\section{Data analysis}

A statistical analysis of the results was performed using the IBM SPSS Statistics 25 package.

Mean weighting outcomes (and standard deviation, SD) for domains, criteria and sub-criteria were calculated and compared between stakeholder subgroups, stratified by:

- Country

- Workplace

- Experience in rare diseases and HTA/reimbursement.

Weight scores differing more than $20 \%$ versus the average group score (e.g. stakeholder subgroup weight vs the overall stakeholder average, or individual country weight vs the overall country average) were highlighted in the results, as this was deemed a suitable cut-off point to show relevant differences.

Field weights were also compared to the expected field weight, meaning the weight if points were divided evenly among the fields (i.e. given the same weight), e.g. 16.67 if 100 points were divided over 6 fields, 25.0 in case of 4 fields, 33.33 points with 3 fields and 50.0 in case of 2 fields.

The Spearman's rank correlation coefficient was calculated to verify whether there were statistically significant correlations within groups of stakeholders (workplace, HTA experience and rare disease experience) and weighting results for domains, criteria and sub-criteria at the $\mathrm{p}<0.05$ level.

Variance analysis was used to check whether there were statistically significant differences $(\mathrm{p}<0.05)$ between countries, workplace, experience in rare diseases and/or HTA/reimbursement in assigning a weight to domains, criteria and sub-criteria.

Missing or incorrect data (e.g. a total over- or underweighting) in one section (domains, criteria, sub-criteria) led to the disqualification of the complete section, i.e. no score. If the data of the respondent in other sections were correctly filled in, these were counted. Missing data happened in 4 instances of 141 (domains section not filled in correctly). One person did not fill in any metrics data (such as workplace or involvement in HTA/rare diseases etc.) and therefore all weight scores of this person were not taken into account. This resulted in a total of 140 respondents with completed data: 137 persons with $100 \%$ valid score data and 3 persons with partially included data.

A Cronbach's Alpha coefficient was calculated to verify if the questionnaire tool was reliable (consistent) and valid. 


\section{Weight score balancing}

Field weights were calculated based on the sum of the average 'workplace' scores as the authors believe the most relevant experience and viewpoints of the respondent are determined by the working environment. The average workplace weights are seen as a more relevant basis for the total field average than a score based on country weights, or stratification by professional background or experience in HTA/rare diseases. Each workplace average was counted once to generate the overall field weight. In an actual weighting process during HTA it can also be expected that different stakeholders will be represented, therefore this is likely to most accurately reflect HTA practice.

\section{RESULTS}

\section{Study overview}

In total 211 questionnaires were sent out and 141 stakeholders responded or were interviewed (response rate 67\%): 37 from Kazakhstan (26\% of all respondents), Romania 22 (16\%), Poland 20 (14\%), Turkey 20 (14\%), the Netherlands $16(11 \%)$,

Table 1. Kruskal-Wallis test values between country weights attached to domains, criteria and sub-criteria. Fields that did not show statistical significance $(\mathrm{p}>0.05)$ are highlighted in grey.

\begin{tabular}{|c|c|c|}
\hline Category & Evidem field & Kruskal-Wallis value; p-value \\
\hline \multirow{6}{*}{ Domains } & Need for intervention & $\mathrm{Z}_{\text {Kruskal-Wallis }}=35.98 ; \mathrm{p}<0.001$ \\
\hline & Comparative outcomes of intervention & $\mathrm{Z}_{\text {Kruskal-Wallis }}=28 ; \mathrm{p}<0.001$ \\
\hline & Type of benefit of intervention & $\mathrm{Z}_{\text {Kruskal-Wallis }}=36.14 ; \mathrm{p}<0.001$ \\
\hline & Economic consequences of intervention & $\mathrm{Z}_{\text {Kruskal-Wallis }}=19.83 ; \mathrm{p}<0.001$ \\
\hline & Knowledge about intervention & $\mathrm{Z}_{\text {Kruskal-Wallis }}=27.72 ; \mathrm{p}<0.001$ \\
\hline & Population priorities & $\mathrm{Z}_{\text {Kruskal-Wallis }}=34.15 ; \mathrm{p}<0.001$ \\
\hline \multirow{15}{*}{ Criteria } & Disease severity & $\mathrm{Z}_{\text {Kruskal-Wallis }}=12.79 ; \mathrm{p}<0.05$ \\
\hline & Size of population & $\mathrm{Z}_{\text {Kruskal-Wallis }}=39.02 ; \mathrm{p}<0.001$ \\
\hline & Unmet needs & $\mathrm{Z}_{\text {Kruskal-Wallis }}=15.45 ; \mathrm{p}<0.001$ \\
\hline & Comparative effectiveness & $\mathrm{Z}_{\text {Kruskal-Wallis }}=24.52 ; \mathrm{p}<0.001$ \\
\hline & Comparative safety/tolerability & $\mathrm{Z}_{\text {Kruskal-Wallis }}=14.6 ; \mathrm{p}<0.05$ \\
\hline & Comparative patient-perceived health/pros & $\mathrm{Z}_{\text {Kruskal-Wallis }}=13.05 ; \mathrm{p}<0.05$ \\
\hline & Type of preventive benefit & $Z_{\text {Kruskal-Wallis }}=8.48 ; \mathrm{p}>0.05$ \\
\hline & Type of therapeutic benefit & $Z_{\text {Kruskal-Wallis }}=8.61 ; \mathrm{p}>0.05$ \\
\hline & Comparative cost consequences - cost of intervention & $\mathrm{Z}_{\text {Kruskal-Wallis }}=14,84 ; \mathrm{p}<0.05$ \\
\hline & Comparative cost consequences - other medical costs & $\mathrm{Z}_{\text {Kruskal-Wallis }}=10.46 ; \mathrm{p}>0.05$ \\
\hline & Comparative cost consequences - non-medical costs & $\mathrm{Z}_{\text {Kruskal-Wallis }}=9.15 ; \mathrm{p}>0.05$ \\
\hline & Quality of evidence & $\mathrm{Z}_{\text {Kruskal-Wallis }}=11.26 ; \mathrm{p}>0.05$ \\
\hline & Expert consensus/clinical practice guidelines & $\mathrm{Z}_{\text {Kruskal-Wallis }}=8.4 ; \mathrm{p}>0.05$ \\
\hline & Rare disease & $\mathrm{Z}_{\text {Kruskal-Wallis }}=9.16 ; \mathrm{p}>0.05$ \\
\hline & Other priorities & $\mathrm{Z}_{\text {Kruskal-Wallis }}=6.1 ; \mathrm{p}>0.05$ \\
\hline \multirow{9}{*}{ Subcriteria } & Impact on life expectancy & $\mathrm{Z}_{\text {Kruskal-Wallis }}=12.79 ; \mathrm{p}<0.05$ \\
\hline & Impact on morbidity & $\mathrm{Z}_{\text {Kruskal-Wallis }}=17.32 ; \mathrm{p}<0.01$ \\
\hline & Impact on patient qol & $\mathrm{Z}_{\text {Kruskal-Wallis }}=10.75 ; \mathrm{p}>0.05$ \\
\hline & Impact on caregiver qol & $\mathrm{Z}_{\text {Kruskal-Wallis }}=19.22 ; \mathrm{p}<0.01$ \\
\hline & Other medical costs to healthcare system & $\mathrm{Z}_{\text {Kruskal-Wallis }}=36.34 ; \mathrm{p}<0.001$ \\
\hline & Medical cost to patient & $\mathrm{Z}_{\text {Kruskal-Wallis }}=32.86 ; \mathrm{p}<0.001$ \\
\hline & Patient/caregiver productivity & $\mathrm{Z}_{\text {Kruskal-Wallis }}=17.08 ; \mathrm{p}<0.01$ \\
\hline & Costs to wider social care system & $\mathrm{Z}_{\text {Kruskal-Wallis }}=8.77 ; \mathrm{p}>0.05$ \\
\hline & Non-medical cost to patients & $\mathrm{Z}_{\text {Kruskal-Wallis }}=14.27 ; \mathrm{p}<0.01$ \\
\hline
\end{tabular}


Russia 16 (11\%) and Ukraine 10 (7\%). Medical professionals accounted for the majority of all respondents; $90 \%$ in Ukraine, $88 \%$ in Russia, Romania $86 \%$, Poland $70 \%$, Turkey $65 \%$, Kazakhstan $62 \%$ and the Netherlands $31 \%$.

In most countries the largest percentage of respondents worked for the pharmaceutical industry: Netherlands $63 \%$, Poland 55\%, Russia 50\%, Turkey $40 \%$, Romania 36\%, Kazakhstan $27 \%$ and Ukraine $30 \%$. The second largest group respondents in all countries worked for either government agencies or universities: Ukraine 50\% (universities), Russia $38 \%$ (government), Romania 32\% (universities), Poland 30\% (government), Turkey 30\% (universities), Kazakhstan 19\% (universities).

Regardless of their current profession, many interviewees reported to have been involved in HTA and/or reimbursement processes at some point in their professional life: Netherlands 75\%, Russia $75 \%$, Ukraine $70 \%$, Poland 65\%, Turkey $60 \%$, Kazakhstan 51\%, and Romania 50\%.

Interviewees from the Netherlands reported the highest percentage of experience with rare diseases $(81 \%)$, followed by Poland and Turkey (both $70 \%$ ), then Ukraine (60\%), Romania (50\%), Russia (44\%) and Kazakhstan (32\%).

\section{EVIDEM weighting results per country}

EVIDEM weighting results per country - Domains

Among the EVIDEM domains 'Need for intervention' was assessed as the most important (i.e. most points given in the weighting) by the respondents in 4 out 7 target countries: Romania (average weight $28.6 \pm 9.8)$, the Netherlands $(28.4 \pm 11.1)$, Russia $(26.5 \pm 12.9)$ and Turkey $(26.5 \pm 15)$.

Respondents from Kazakhstan scored 'Type of benefit of intervention' $(20.6 \pm 10.5)$ as the highest as did Polish respondents $(24.5 \pm 12.2)$. Ukraine rated 'Economic consequences of intervention' first (26.9 \pm 9.6$)$ followed closely by 'Type of benefit of intervention' (25.4 \pm 12.6$)$. The domain 'Population Priorities' was uniformly given a low priority, i.e. the lowest importance in 5 countries (Netherlands, Romania, Russia, Poland, Turkey) with Kazakhstan and Ukraine also giving this domain a weight on the lower end. Other domains showed more mixed results between countries. See Figure 2 for all country domain weighting scores.

Statistical analysis showed a statistically significant difference between countries for all 6 domains. For the $\mathrm{Z}_{\text {Kruskal-Wallis }}$ values, please refer to Table 1. Criteria and sub-criteria partially showed significant differences between countries for several fields. Please refer to Table 1.

\section{EVIDEM weighting results per country - Criteria}

Criteria weights within the Domain Need for intervention

The 'Need for intervention' domain contains 3 criteria: 'Disease severity', 'Size of the population' and 'Unmet needs'. 'Disease severity' was the most highly rated in Kazakhstan $(42.6 \pm 16.8)$ Romania

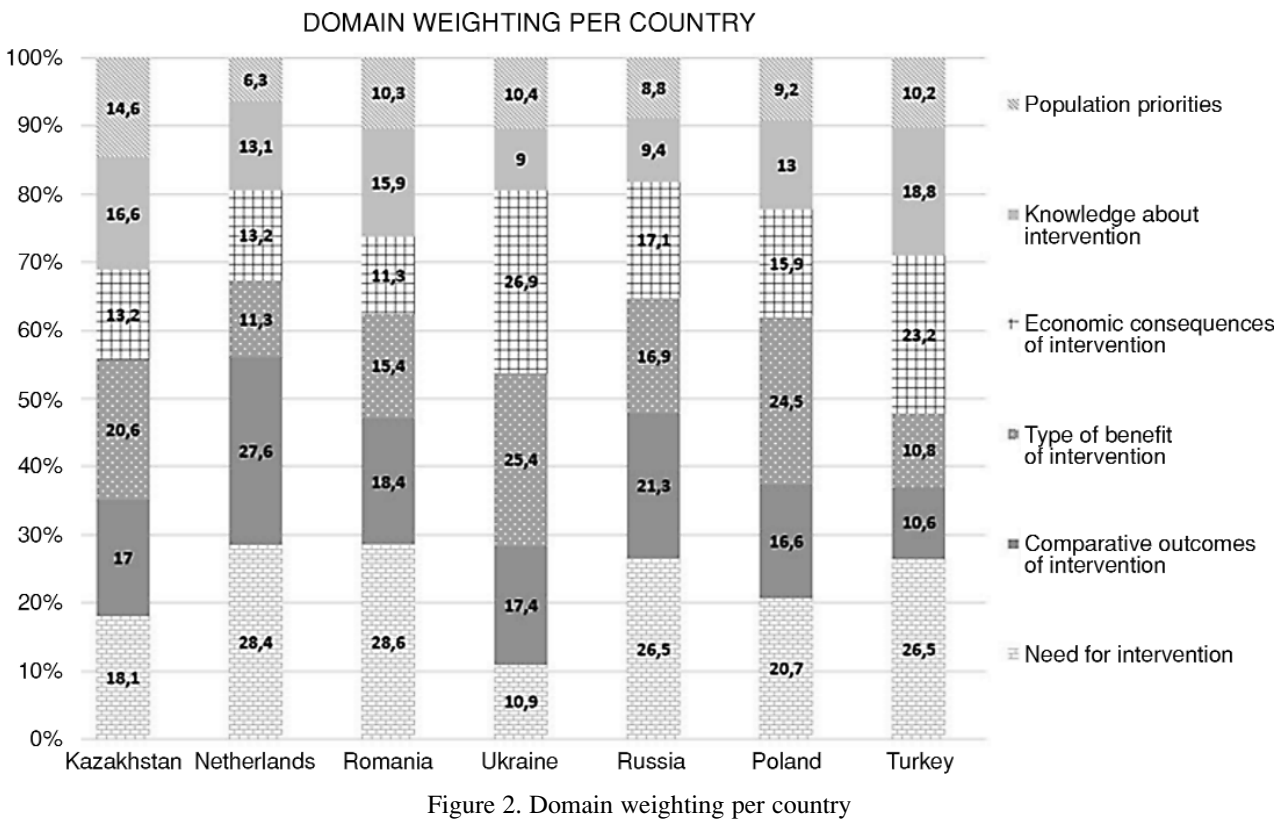




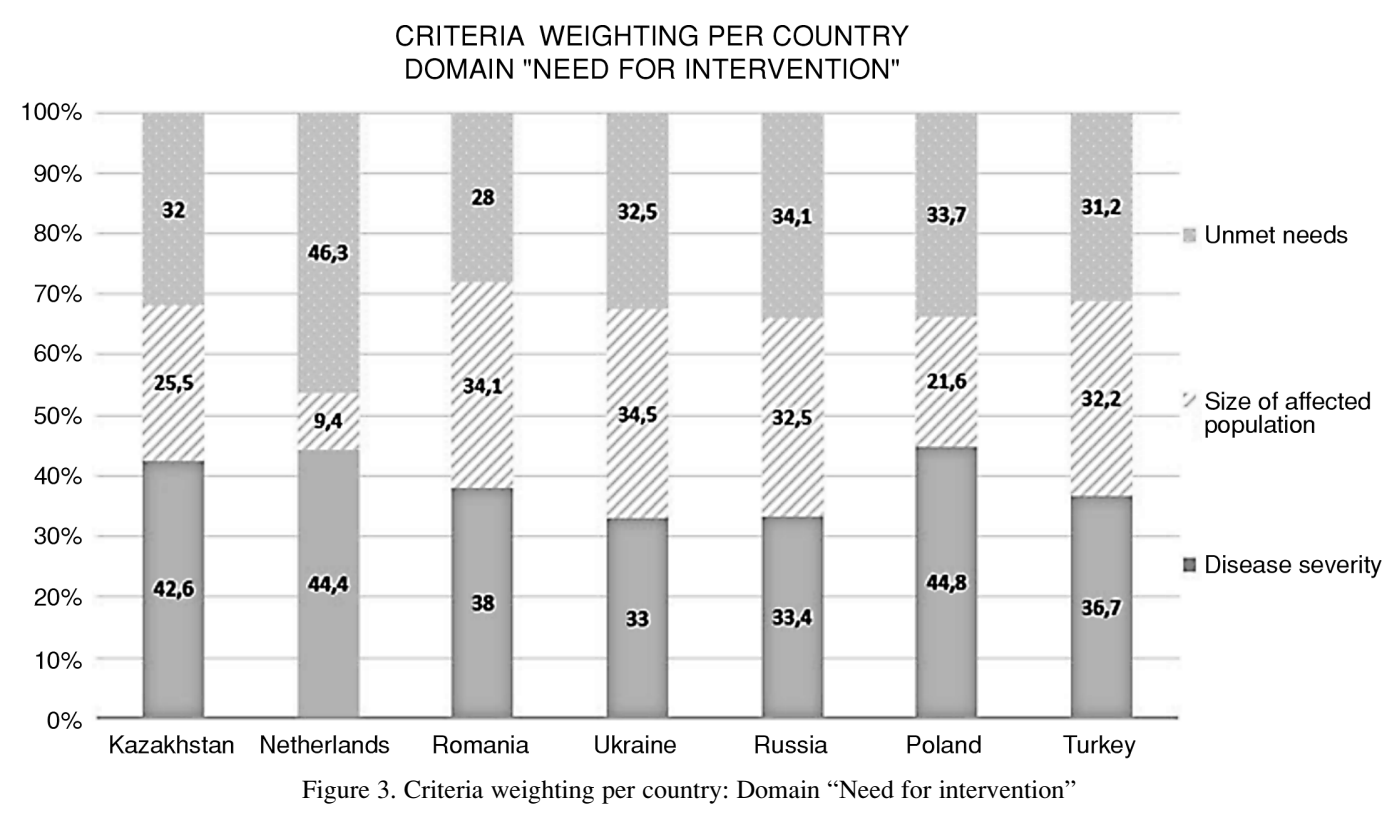

$(38 \pm 21.6)$, Poland $(44.8 \pm 17.1)$ and Turkey $(36.7$ \pm 9.9). 'Unmet needs' received the highest weight by Dutch $(46.3 \pm 14.7)$ and Russian respondents (34.1 \pm 14$)$. Ukraine rated 'Size of the affected population' $(34.5 \pm 13.8)$ as the highest. Turkey, Russia and Ukraine divided importance generally evenly over the 3 criteria, whereas the Netherlands had 1 very low weight score: 'Size of the affected population' $(9.4 \pm 7.0)$. Please refer to Figure 3 for all country weighting scores for the criteria in the Domain Need for Intervention.

\section{Criteria weights within the Domain Comparative outcomes of intervention}

The 'Comparative outcomes of intervention domain' contains the criteria 'Comparative effectiveness', 'Comparative safety/tolerability' and 'Comparative patient perceived health/PRO's'. The respondents from all 7 countries marked 'Comparative Effectiveness' on average as the most relevant criterion: Russia (50 \pm 19.5$)$, The Netherlands (45.4 \pm 14.1) Romania (42.5 \pm 13.2), Turkey (40.3 \pm 4.4$)$, Poland $(39.7 \pm 15.3)$, Kazakhstan $34.3 \pm 11.1$ and Ukraine $(36.4 \pm 11.8)$. The other 2 criteria were more diversely weighted, with 'Comparative Safety/Tolerability' receiving 4 second-highest weights and 'Comparative PRO's' 3. Kazakhstan weighted the 3 criteria almost equally. Please refer to Figure 4 for all country weighting scores for the criteria in the Domain Comparative Outcomes of Intervention.
Criteria weights within the Domain Type of benefit

In the 'Type of benefit' domain (containing 2 criteria), respondents from all countries rated 'Therapeutic benefits' on average higher than type of 'Preventative benefits', e.g. Kazakhstan (58.8 \pm 17.1), the Netherlands (51.6 \pm 14.3$)$, Romania (55 \pm 11.5), Ukraine $(56 \pm 20.1)$, Russia (58 \pm 20.4$)$, Poland (50.8 \pm 14$)$ and Turkey (51.3 \pm 8.3$)$.

Criteria weights within the Domain Economic consequences of intervention

In the 'Economic consequences of intervention' domain ( 3 criteria), respondents from all countries uniformly rated the 'Comparative cost of intervention' as the most important criterion: Russia (52.4 \pm 28.9$)$, Turkey (51.3 \pm 12.2$)$, Netherlands $(47.7 \pm 20.0)$, Kazakhstan $(44.9 \pm 13.3)$, Romania $(40.2 \pm 14)$, Poland $(39.0 \pm 12.9)$ and Ukraine (34.9 \pm 8.5 ). The other 2 criteria, Comparative medical costs and Non-medical costs, were mixed but relatively evenly weighted in the countries. Please refer to Figure 5 for all country weighting scores for the criteria in the Domain Economic consequences of intervention.

\section{Criteria weights within the Domain Knowledge of Intervention}

In the domain 'Knowledge of intervention' (2 criteria), respondents from all countries were in agreement 'Quality of data' is deemed of higher importance than 'Expert consensus/clinical practice 
guidelines': Russia (73.8 \pm 18.6), Poland (62.0 \pm 19.2), Turkey (63.0 \pm 10.3), Kazakhstan (62.6 \pm 16.1), the Netherlands (62.2 \pm 19.1$)$; Romania (58.4 $\pm 17.5)$ and Ukraine (53.0 \pm 11.6$)$.

Criteria weights within the Domain Population priorities

The 'Population priorities' domain, the lowest weighted domain, contains 2 criteria: Rare Diseases and Other Priorities. There was no overall consensus between countries. Countries that rated rare diseases as the highest priority in this domain were the Netherlands (60.0 \pm 24.4), Ukraine (52.5 \pm 33.2), Russia $(52.5 \pm 31.1)$ and Poland $(50.8 \pm 24.9)$. Other priorities were rated higher in Romania (59.1 \pm 16.3$)$, Kazakhstan (56.4 \pm 22.7$)$ and Turkey (55.0 \pm 20.7$)$.

Statistical analysis showed a statistically significant difference $\left(Z_{\text {Kruskal-Wallis) }}\right.$ values between countries for 8 of the 15 criteria, please refer to Table 1.

\section{EVIDEM weighting results per country - Sub-cri- teria}

Sub-criteria weights within the Criterion Disease severity

Within the 'Disease severity' criterion (having 4 sub-criteria), Romanian (35.7 \pm 19.7$)$ and Polish $(35.3 \pm 15.3)$ respondents weighted 'Impact on lifeexpectancy' as the most important while respon- dents from all other countries placed the highest value on 'Patient QoL': Turkey (37.2 \pm 8); Kazakhstan (34.5 \pm 13.8); Russia (33.9 \pm 10.4); Ukraine (33.7 \pm 6.6$)$; Netherlands $(33.1 \pm 10.1)$.

\section{Sub-criteria weights within the Criterion Other med-} ical costs

Of the 2 sub-criteria under the criterion 'Other medical costs', 'Medical costs to patient' was given the most weight by respondents in Kazakhstan (53.9 $\pm 19.3)$, the Netherlands $(51.3 \pm 11.6)$, Romania $(51.4 \pm 13.1)$ and Ukraine $(59.0 \pm 23.2)$. Sub-criterion 'Other medical costs to healthcare system' was rated higher and with a larger numerical weight in Russia $(69.7 \pm 24.2)$ Poland $(61.5 \pm 16.6)$ and Turkey $(78.1 \pm 23)$.

\section{Sub-criteria weights within the Criterion Non-med-} ical costs

Of the 3 sub-criteria under the Criterion 'Nonmedical costs' the sub-criterion 'Patient/caregiver productivity' was rated the highest in 5 countries (Russia $58.7 \pm 28.9)$; Poland (44,9 \pm 18.1); The Netherlands (40.5 \pm 15.6); Romania (40.2 \pm 13.9) and Kazakhstan (35.9 \pm 14.4$)$, while Ukraine (41 \pm 15.8) and Turkey $(36.8 \pm 10.2)$ rated costs to the wider social care system as the most important. 'Non-medical costs to patients' was rated the lowest in 5 out of 7 countries.

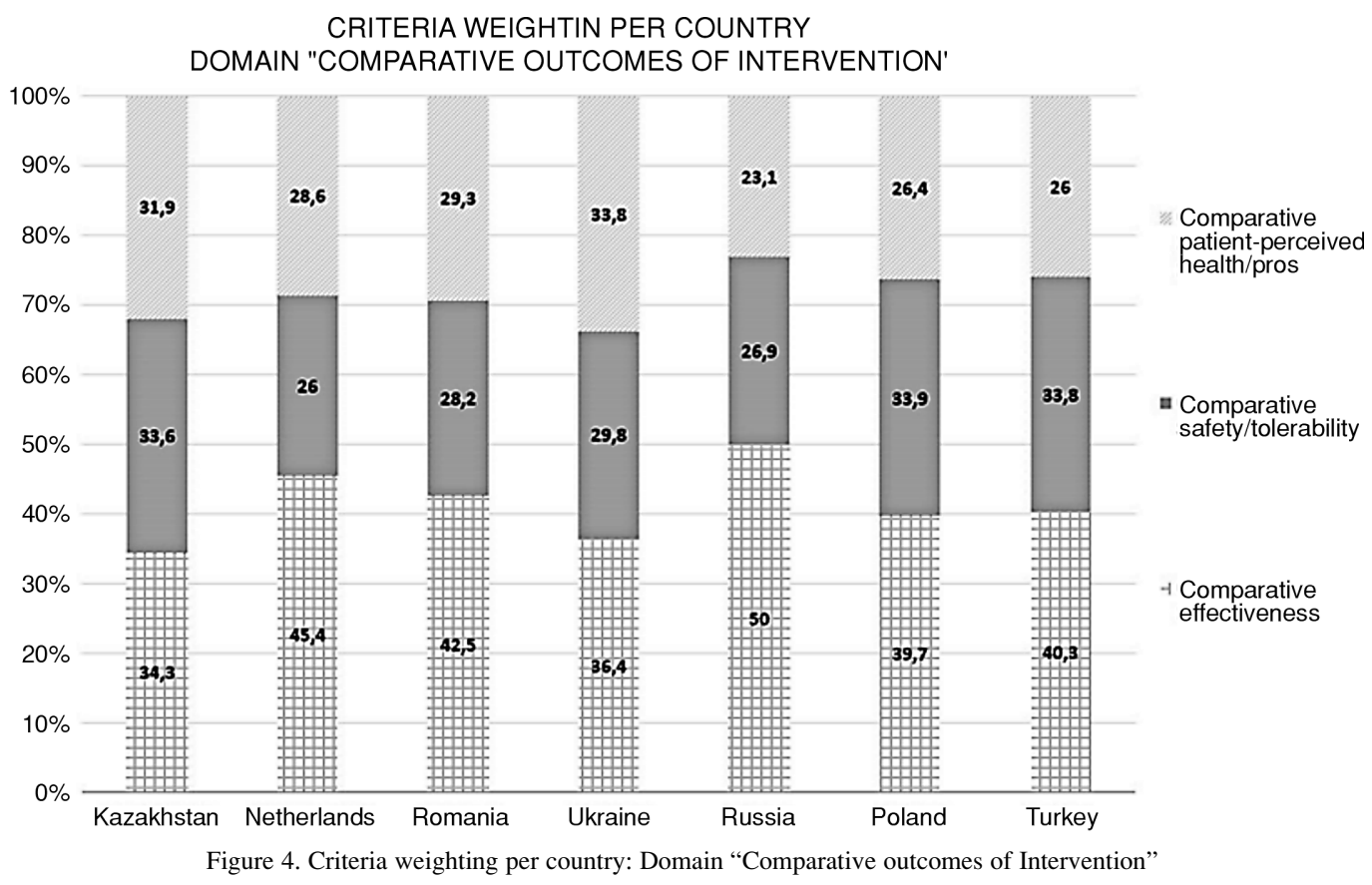




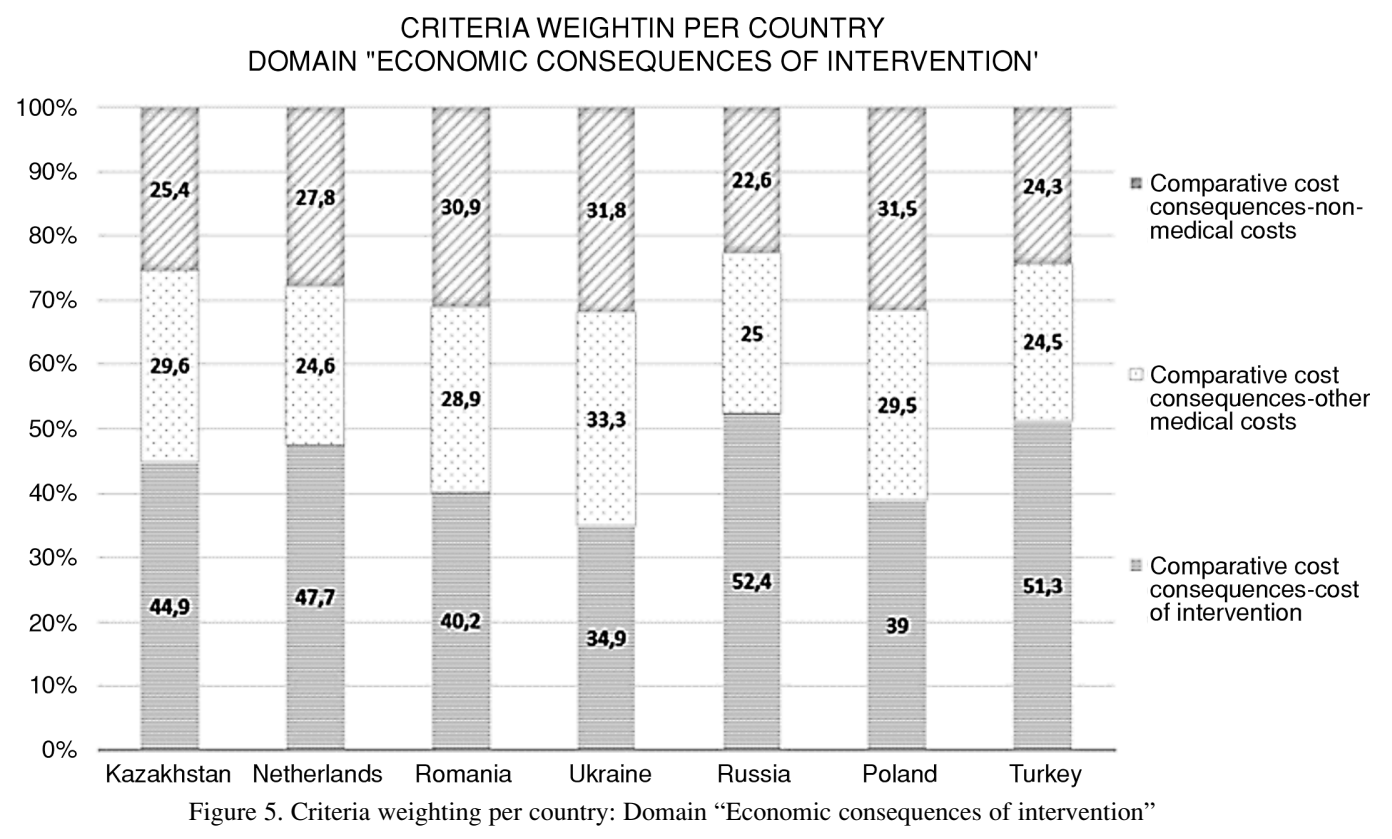

\section{EVIDEM weighting results stratified by work- place}

\section{EVIDEM weighting results per workplace - Domains}

Similar to the country based results, when stratified for workplace (regardless of country of origin) the domain 'Need for Intervention' was rated highest with an average weight of 23.8 (43\% above the expected weight of 16.67 when even spread over the 6 domains) and 'Population Priorities' was rated the lowest with a weight of 10.7. The 'Need for Intervention' domain did show high variability between workplace subgroups, with 4 out of 7 weightings deviating more than $20 \%$ of the average workplace weight. Domain weights by patient organizations differed strongly from the average workplace weight scores, but the low number of respondents $(n=2)$ limits the validity of these results (see 4.1 Study limitations). 'Population priorities' was rated more than $30 \%$ above the workplace average by both Government officials and the group of 'Other' respondents, albeit both still lower than the expected field weight of 16.67. Comparative outcomes of intervention were relatively underweighted by Government officials, both below the expected score and $24 \%$ lower than the overall average for this field.

Domain weighting scores from respondents working in university and industry were all within $+/-15 \%$ of the mean field scores, i.e. they showed no significant outliers.

\section{EVIDEM weighting results per workplace - Criteria}

Criteria in the Domains Need for intervention, Comparative outcomes of intervention and Type of benefit

Within the 'Need for intervention' domain the 'Disease severity' criterion was scored highest with 40.3 (21\% above the expected score of $33.33 \%)$ and scores for 'Population size' and 'Unmet needs' were around 30 .

Among the 3 criteria in the domain 'Comparative outcomes of intervention', 'Comparative effectiveness' was weighted highest overall with a score of almost 40, with the other 2 criteria ('Comparative safety/tolerability' and 'Comparative PRO's') having scores near 30. Only minor differences were seen in the weighting between 'Type of preventive benefit' or 'Type of therapeutic benefit': 44.5 and 55.5, with no score deviating more than $20 \%$ from the overall workplace average.

Domains Comparative cost-consequences and Knowledge about intervention

The comparative 'Cost of intervention' criterion was rated highest with 44 points, with the other 2 criteria having weight scores of around 28 (Comparative other medical costs and non-medical costs).

Within the 'Knowledge about intervention' domain (2 criteria) 'Quality of evidence' was rated higher $(60 \%)$ than 'Expert consensus/clinical guide- 
lines' $(40 \%)$. In the 'Population priorities' domain both 'Rare diseases' and 'Other priorities' were weighted evenly, near $50 \%$.

\section{EVIDEM weighting results per workplace - Sub- Criteria}

In the 'Disease severity' criterion with 4 subcriteria (expected score 25), the sub-criterion 'Impact on patient quality-of-life' was rated highest at $33.0(+32 \%$ above the expected score), with 'Impact on life-expectancy' also rated above the expected score of $25(28.9,+16 \%)$. 'Impact on morbidity' was scored low $(21.7,-13 \%)$ and 'Impact on caregiver QoL', a criterion that can be viewed as relevant for debilitating rare diseases, was scored the lowest by respondents from all workplaces at 16.4 (-34\% below the expected score). The stakeholder group "Other" ranked "Impact on caregiver QoL" relatively high: $42.8 \%$ higher than the average workplace score, but still lower than 25 points overall.

In the criterion 'Comparative Other medical costs' both 'Medical costs to patients' and 'Other medical costs to the healthcare system' were rated evenly around $50 \%$.

Lastly, in the criterion 'Comparative cost-consequences: non-medical costs' the 3 sub-criteria were rated not far apart, with 'Patient/Caregiver productivity' rated highest (38 vs 33.33 expected average).

For a detailed overview of the stakeholder weighting results stratified per workplace, please refer to Table 2.

\section{Overall EVIDEM weighting results - HTA vs non-HTA respondents and RD experience vs non- RD experience}

\section{HTA experienced vs non-HTA experienced respon- dents}

When stratified for HTA experience, the most notable differences in the domain scores can be seen for 'Need for intervention' with a 4.9 points lower weighting $(-18.6 \%)$ in HTA experienced respondents vs non-HTA experienced respondents $(\mathrm{F}(1 ; 122)=$ 3.66; $\mathrm{p}<0.05)$. 'Comparative outcomes of intervention' was scored 3.4 points higher $(+21.2 \%)$ by HTA experienced respondents $(\mathrm{F}(1 ; 122)=4.52 ; \mathrm{p}<0.05)$ and 'Economic consequences of intervention' 5.2 points higher $(+39.6 \%, \mathrm{p}>0.05)$. Most of the Criteria were uniformly scored, with only the 'Quality of evidence' criterion differing more than $20 \%$ between both subgroups. This criterion was scored higher than 'Expert consensus/clinical guidelines' by both sub- groups, but respondents with HTA experience rated it higher than those without (66 vs 56). A statistical significant difference was also seen between the weighting scores for the sub-criterion 'Impact on lifeexpectancy’ $(\mathrm{F}(1 ; 125)=6.08 ; \mathrm{p}<0.05)$.

\section{$R D$ experience vs non- $R D$ experience}

When stratified for "Experience with rare diseases", only the weighting of the domain 'Economic consequences' differed more than $20 \%$ between those with and without RD experience. All criteria and sub-criteria were weighted very uniformly between both subgroups, with no weights differing more than $20 \%$. Two fields showed a statistically significant difference between both groups: 'Other priorities' (48.2 vs 56.2, $\mathrm{F}(1 ; 118)=5.7$; $\mathrm{p}<0.05$ ) and 'Comparative outcomes of intervention' (17.3 vs $19.0, \mathrm{~F}(1 ; 120)=3.61 ; \mathrm{p}<0.05)$ were scored lower by respondents with $\mathrm{RD}$ experience.

In general, similarities can be seen between the weighting results stratified for positive HTA and Rare Disease experience, i.e. having either HTA or $\mathrm{RD}$ experience often shows a similar result when stratified for the other experience field.

Please refer to Table 3, Figures 6 and 7 for results stratified by HTA and RD experience.

\section{DISCUSSION}

\section{Study limitations}

Questionnaire validity: sample size and characteristics of respondents

Compared to existing literature this MCDA weighting study includes one of the largest questionnaire populations, with over 140 expert respondents from 7 countries with varying backgrounds from a wide geographical region. The Alpha Cronbach's coefficient was determined to be 0.72 , which indicates that the questionnaire can generally be considered reliable and valid (i.e. having acceptable internal consistency). However, several subgroups are still of limited size, e.g. when stratifying and comparing stakeholder selections (e.g. countries). Statistical significance was therefore difficult to attain for some results and comparative analyses, which can limit validity and extrapolation.

Various stakeholder populations among the respondents were not equally distributed, having a relative overweight in industry, government and university representatives and with only a few respondents in the groups of patients and pharmacy workers. This could lead to an imbalance in the overall weight averages, although the authors cor- 


\begin{tabular}{|c|c|c|c|c|c|c|c|c|c|c|c|c|c|}
\hline 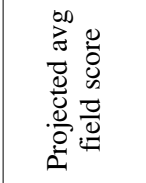 & & \multicolumn{6}{|c|}{$\begin{array}{l}\tilde{b} \\
\underline{.}\end{array}$} & \multicolumn{3}{|c|}{$\stackrel{m}{m}$} & \multicolumn{3}{|c|}{$\underset{m}{m}$} \\
\hline 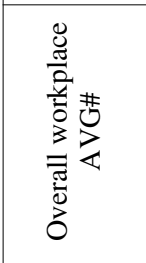 & & 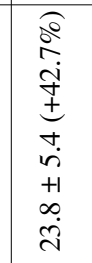 & $\begin{array}{l}\widehat{0} \\
a \\
0 \\
\pm \\
\pm \\
n \\
n \\
+1 \\
n \\
a \\
a\end{array}$ & 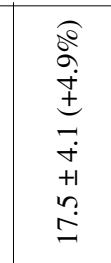 & 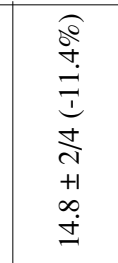 & 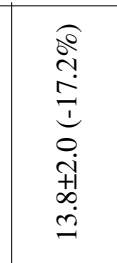 & 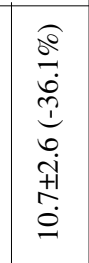 & 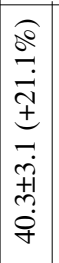 & 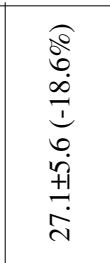 & 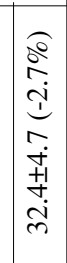 & 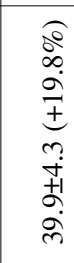 & 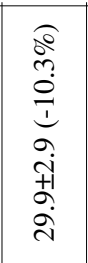 & 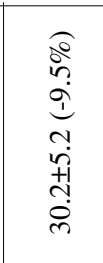 \\
\hline $\begin{array}{l}\bar{\Xi} \\
\bar{\Xi}\end{array}$ & $\Sigma$ & 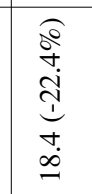 & 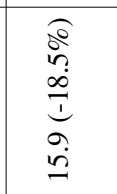 & 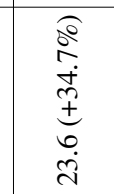 & $\begin{array}{l}\widehat{d} \\
b \\
\dot{+} \\
\pm \\
\dot{+} \\
\stackrel{a}{a}\end{array}$ & 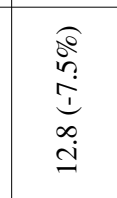 & 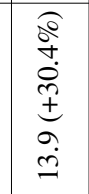 & 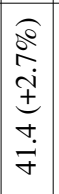 & 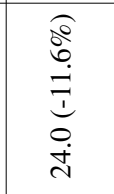 & $\begin{array}{l}0 \\
0 \\
0 \\
0 \\
+ \\
0 \\
0 \\
\dot{m} \\
\dot{m}\end{array}$ & 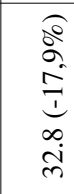 & 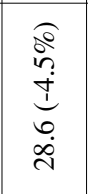 & 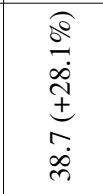 \\
\hline 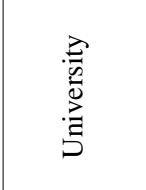 & $\Sigma$ & $\begin{array}{l}\widehat{\sigma} \\
\stackrel{0}{1} \\
\stackrel{i}{i} \\
m \\
\stackrel{i}{v}\end{array}$ & $\begin{array}{l}\stackrel{0}{o} \\
\stackrel{0}{+} \\
\stackrel{+}{\infty} \\
\stackrel{\infty}{-1}\end{array}$ & $\begin{array}{l}\text { of } \\
\stackrel{0}{i} \\
0 \\
0 \\
0\end{array}$ & 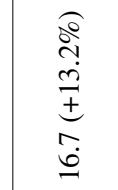 & 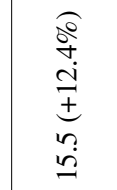 & $\begin{array}{l}\widehat{a} \\
\stackrel{0}{0} \\
\stackrel{0}{0} \\
\vdots \\
a \\
a\end{array}$ & 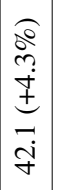 & 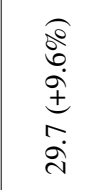 & 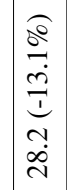 & $\begin{array}{l}\widehat{o} \\
+ \\
0 \\
0 \\
+1 \\
\infty \\
\dot{m}\end{array}$ & 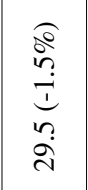 & 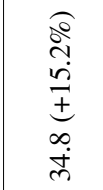 \\
\hline 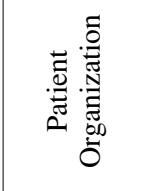 & $\Sigma$ & 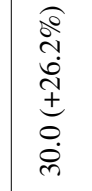 & 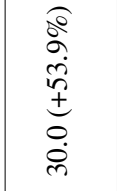 & 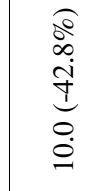 & 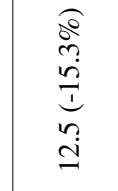 & 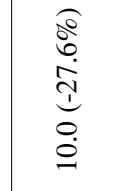 & 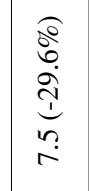 & 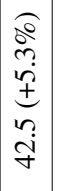 & 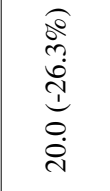 & 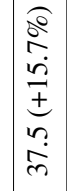 & 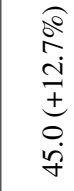 & 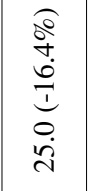 & 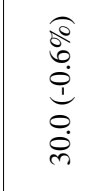 \\
\hline 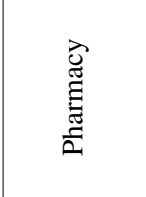 & $\Sigma$ & $\begin{array}{c}\stackrel{\sigma o}{o} \\
\stackrel{\dot{m}}{\dot{m}} \\
\stackrel{+}{m} \\
\stackrel{m}{m}\end{array}$ & $\begin{array}{l}\widehat{0} \\
\stackrel{0}{0} \\
0 \\
0 \\
0 \\
0 \\
0\end{array}$ & 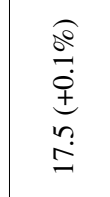 & 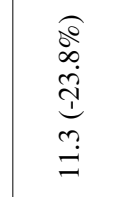 & 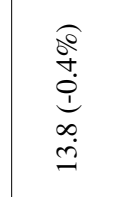 & $\begin{array}{l}\widehat{o} \\
0 \\
0 \\
0 \\
0 \\
0\end{array}$ & 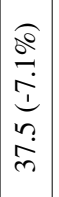 & 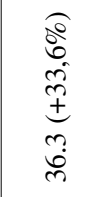 & 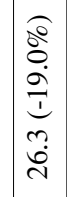 & 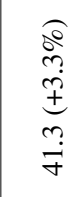 & $\begin{array}{l}\widehat{O} \\
\dot{0} \\
\dot{d} \\
\infty \\
\dot{i} \\
\dot{i}\end{array}$ & $\begin{array}{l}\widehat{0} \\
\dot{0} \\
\dot{9} \\
0 \\
\dot{8}\end{array}$ \\
\hline 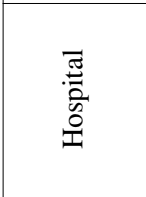 & $\Sigma$ & 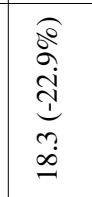 & 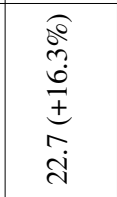 & 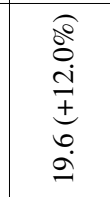 & 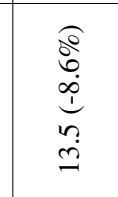 & 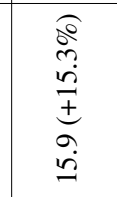 & $\begin{array}{l}\widehat{o} \\
\stackrel{0}{0} \\
0 \\
0 \\
0\end{array}$ & 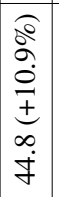 & 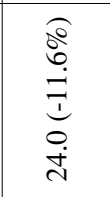 & 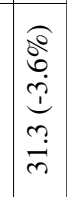 & 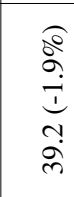 & $\begin{array}{l}\widehat{\sigma} \\
\stackrel{0}{0} \\
\dot{+} \\
0 \\
0 \\
\text { d. }\end{array}$ & 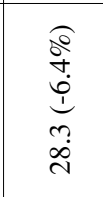 \\
\hline 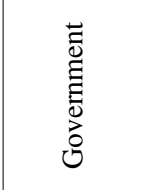 & $\Sigma$ & $\begin{array}{l}\stackrel{a}{0} \\
\stackrel{5}{5} \\
\stackrel{5}{a} \\
\stackrel{a}{a}\end{array}$ & 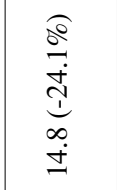 & $\begin{array}{l}\widehat{o} \\
\stackrel{a}{+} \\
\stackrel{+}{ \pm} \\
\vec{a}\end{array}$ & 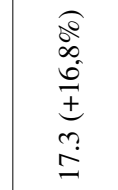 & $\begin{array}{l}\widehat{Q} \\
\stackrel{0}{0} \\
\dot{+} \\
\pm \\
0 \\
\dot{ \pm}\end{array}$ & $\begin{array}{l}\widehat{o} \\
\stackrel{0}{0} \\
\stackrel{0}{ \pm} \\
0 \\
\dot{ \pm}\end{array}$ & 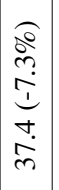 & 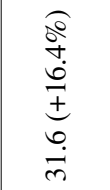 & 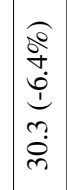 & $\begin{array}{l}\widehat{\sigma} \\
\sigma \\
\dot{0} \\
\pm \\
n \\
\sigma \\
q\end{array}$ & $\begin{array}{l}\stackrel{\sigma}{\theta} \\
\vec{m} \\
\dot{m} \\
\infty \\
\dot{m}\end{array}$ & 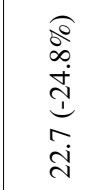 \\
\hline 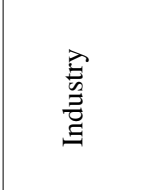 & $\Sigma$ & 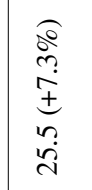 & 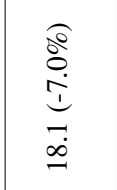 & 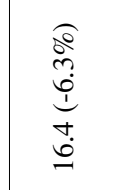 & 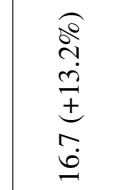 & $\begin{array}{l}\stackrel{Q}{o} \\
\stackrel{\sim}{i} \\
\pm \\
\pm \\
\dot{ \pm}\end{array}$ & 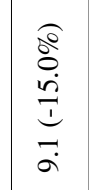 & 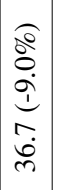 & 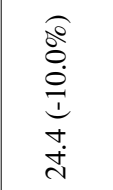 & $\begin{array}{l}\widehat{\sigma} \\
\partial \\
\partial \\
\partial \\
ذ \\
\partial \\
\partial \\
\infty \\
\infty\end{array}$ & 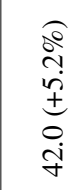 & 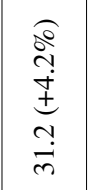 & 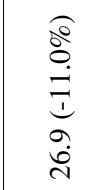 \\
\hline 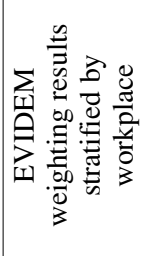 & & 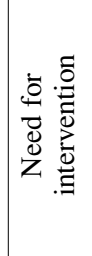 & 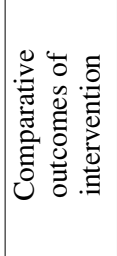 & 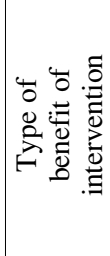 & 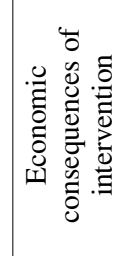 & 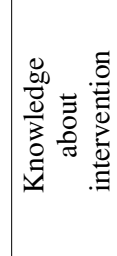 & 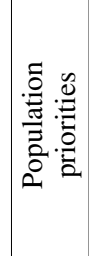 & 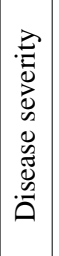 & 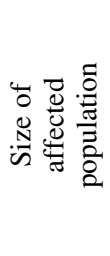 & 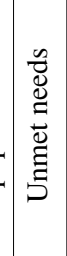 & 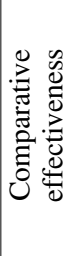 & 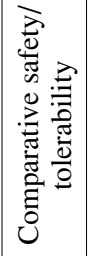 & 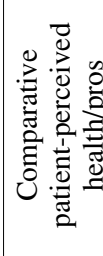 \\
\hline & & & & & & & 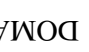 & & & & & & \\
\hline
\end{tabular}




\begin{tabular}{|c|c|c|c|c|c|c|c|c|c|c|c|}
\hline 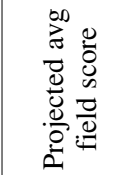 & & \multicolumn{2}{|r|}{ in } & \multicolumn{3}{|c|}{$\stackrel{m}{m}$} & \multicolumn{2}{|r|}{ in } & \multicolumn{2}{|c|}{ in } & \multirow[b]{2}{*}{ 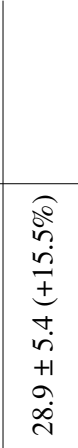 } \\
\hline 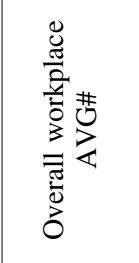 & 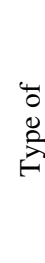 & 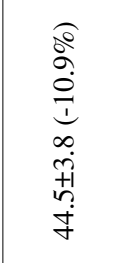 & $\begin{array}{l}0 \\
0 \\
0 \\
0 \\
\pm \\
\infty \\
0 \\
+1 \\
n \\
n \\
n \\
n\end{array}$ & 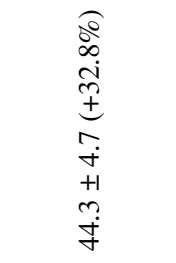 & 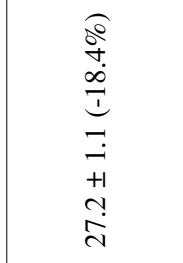 & 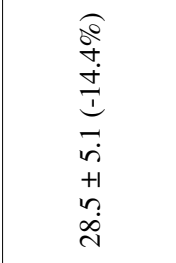 & 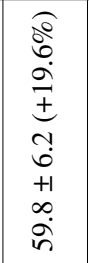 & 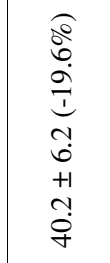 & 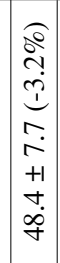 & 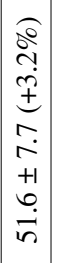 & \\
\hline $\begin{array}{l}\stackrel{\bar{D}}{\bar{z}} \\
\end{array}$ & $\Sigma$ & 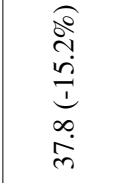 & 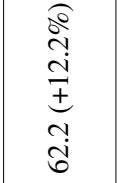 & 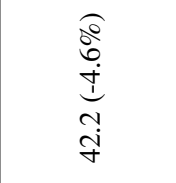 & 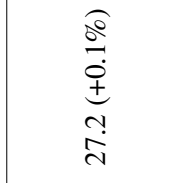 & 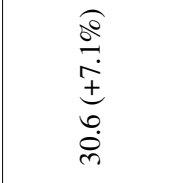 & 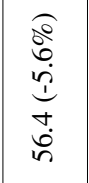 & 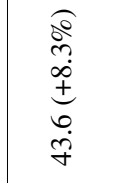 & 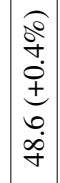 & $\mid \begin{array}{c}0 \\
0 \\
m \\
0 \\
i \\
0 \\
\dot{j} \\
\vec{n}\end{array}$ & 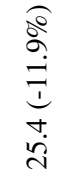 \\
\hline 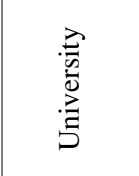 & $\Sigma$ & 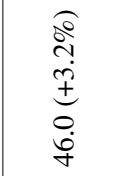 & 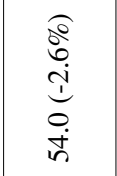 & $\begin{array}{l}\widehat{o} \\
\dot{0} \\
\dot{i} \\
\infty \\
\dot{y} \\
\dot{y}\end{array}$ & 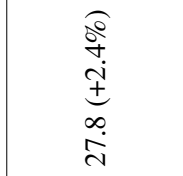 & $\begin{array}{l}0 \\
0 \\
0 \\
0 \\
\pm \\
0 \\
0 \\
0\end{array}$ & $\begin{array}{l}0 \\
0 \\
i n \\
\pm \\
= \\
6\end{array}$ & 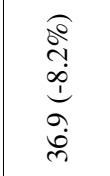 & 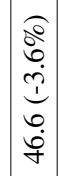 & 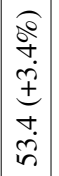 & 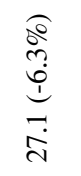 \\
\hline 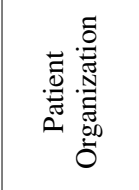 & $\Sigma$ & 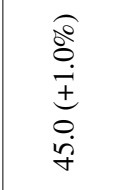 & $\begin{array}{l}\widehat{0} \\
\infty \\
0 \\
0 \\
0 \\
\dot{0} \\
i n\end{array}$ & 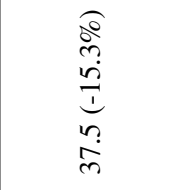 & 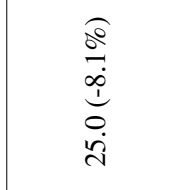 & 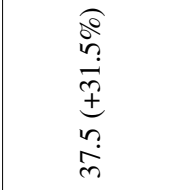 & 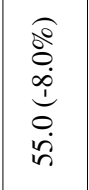 & 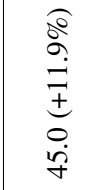 & $\begin{array}{c}2 \\
i \\
i \\
i \\
\pm \\
\pm \\
n \\
i \\
0\end{array}$ & 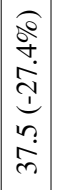 & $\begin{array}{l}\widehat{0} \\
i n \\
\stackrel{0}{1} \\
0 \\
0 \\
\dot{i}\end{array}$ \\
\hline 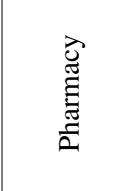 & $\Sigma$ & 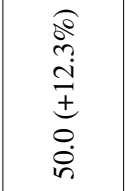 & 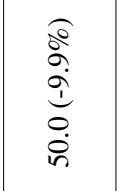 & 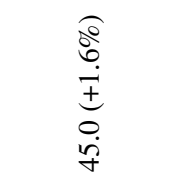 & 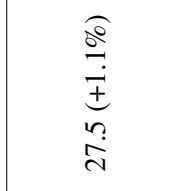 & 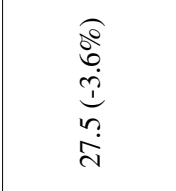 & 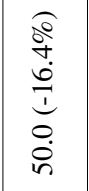 & 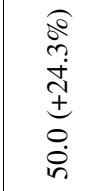 & $\begin{array}{c}0 \\
0 \\
n \\
i \\
i n \\
n \\
n \\
n \\
m\end{array}$ & 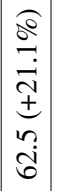 & $\begin{array}{l}\widehat{0} \\
i n \\
0 \\
\infty \\
+ \\
0 \\
\dot{+}\end{array}$ \\
\hline 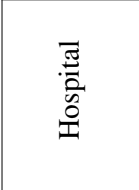 & $\Sigma$ & 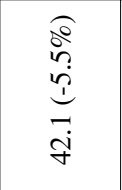 & 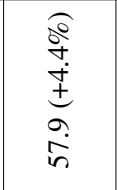 & 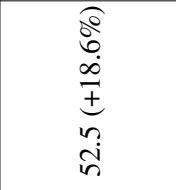 & $\begin{array}{l}\text { o } \\
0 \\
i \\
i \\
n \\
o n \\
i\end{array}$ & 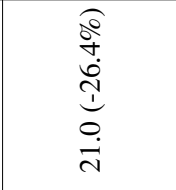 & 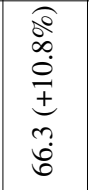 & $\begin{array}{l}\frac{a}{a} \\
\dot{0} \\
\vdots \\
\infty \\
\infty \\
m\end{array}$ & 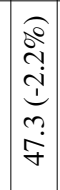 & 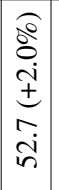 & 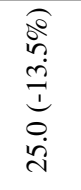 \\
\hline 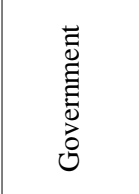 & $\Sigma$ & 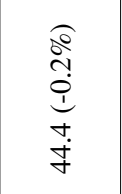 & 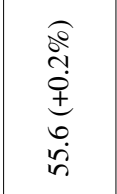 & 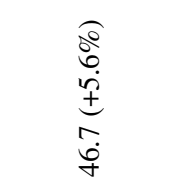 & 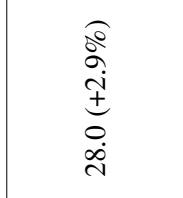 & 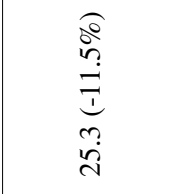 & 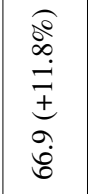 & 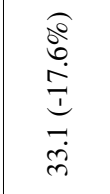 & $\begin{array}{c}a \\
i \\
i \\
i \\
0 \\
\infty \\
\dot{q} \\
\dot{q}\end{array}$ & $\mid \begin{array}{c}0 \\
0 \\
o \\
\infty \\
\pm \\
0 \\
0 \\
b \\
n\end{array}$ & 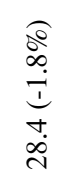 \\
\hline 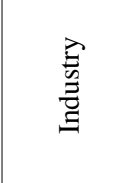 & $\Sigma$ & 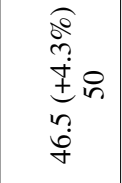 & 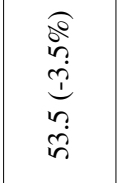 & 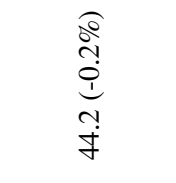 & 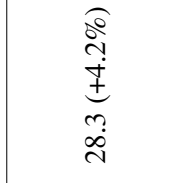 & 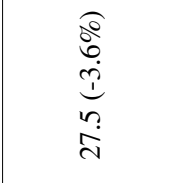 & $\begin{array}{l}\stackrel{0}{8} \\
\stackrel{1}{ \pm} \\
\infty \\
\infty \\
8\end{array}$ & 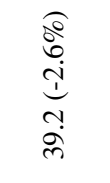 & $\begin{array}{c}c \\
d \\
i \\
o \\
0 \\
\pm \\
+ \\
i \\
i\end{array}$ & 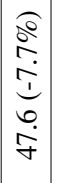 & 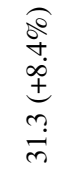 \\
\hline 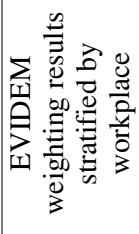 & & 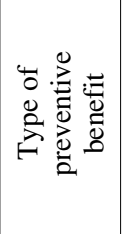 & 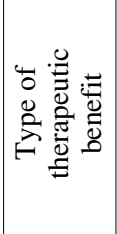 & 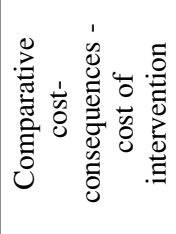 & 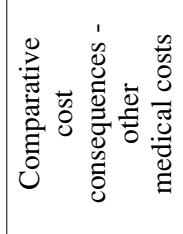 & 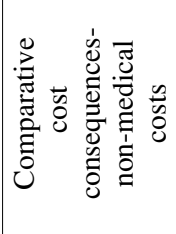 & 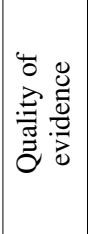 & 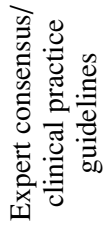 & 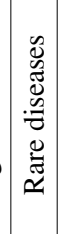 & 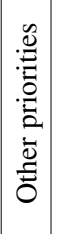 & 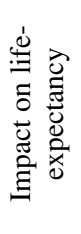 \\
\hline & & & & & & כ] & & & & & \\
\hline
\end{tabular}


Applicability of the evidem multi-criteria decision analysis framework...

\begin{tabular}{|c|c|c|c|c|c|c|c|c|c|}
\hline 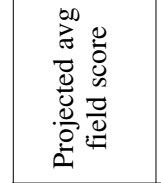 & & \multicolumn{3}{|c|}{$\approx$} & \multicolumn{2}{|c|}{ in } & \multicolumn{3}{|c|}{ लై } \\
\hline 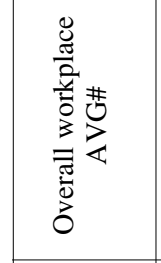 & 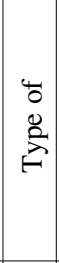 & 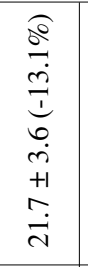 & 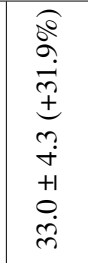 & 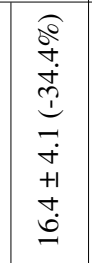 & 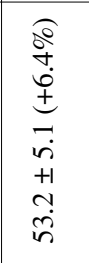 & 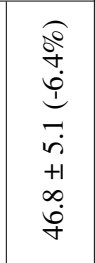 & 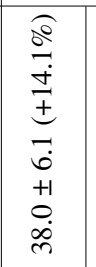 & 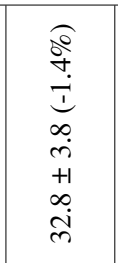 & 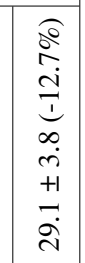 \\
\hline $\begin{array}{l}\overline{\overleftarrow{\Xi}} \\
\bar{\Xi}\end{array}$ & $\Sigma$ & $\begin{array}{l}\widehat{o} \\
\stackrel{0}{n} \\
\stackrel{0}{1} \\
\stackrel{1}{0} \\
\stackrel{0}{0}\end{array}$ & $\begin{array}{l}\text { o } \\
\dot{8} \\
\dot{+} \\
\stackrel{5}{\dot{m}}\end{array}$ & 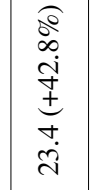 & 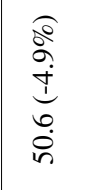 & 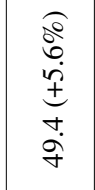 & 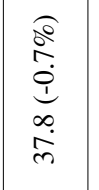 & 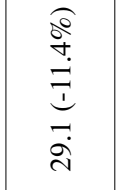 & 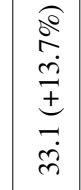 \\
\hline 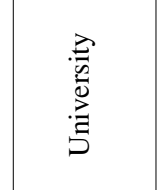 & $\Sigma$ & 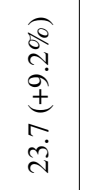 & 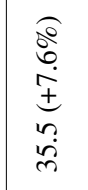 & 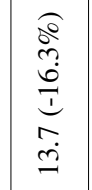 & $\begin{array}{l}0 \\
0 \\
0 \\
0 \\
\pm \\
n \\
n \\
n\end{array}$ & $\begin{array}{l}0 \\
0 \\
0 \\
0 \\
i \\
n \\
0 \\
q\end{array}$ & 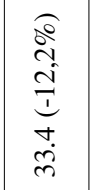 & 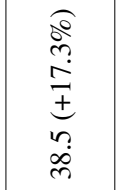 & 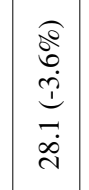 \\
\hline 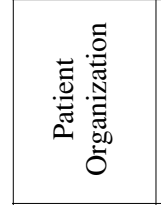 & $\Sigma$ & 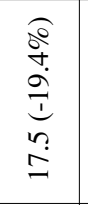 & 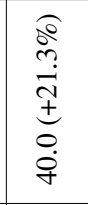 & $\begin{array}{l}0 \\
8 \\
0 \\
0 \\
\pm \\
n \\
= \\
=\end{array}$ & 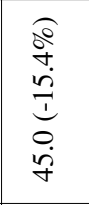 & 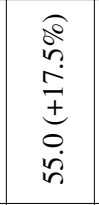 & 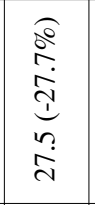 & 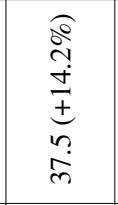 & 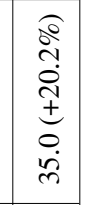 \\
\hline 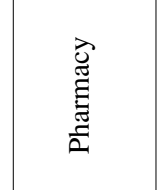 & $\Sigma$ & 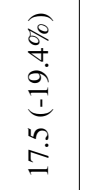 & 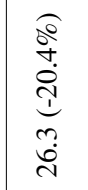 & 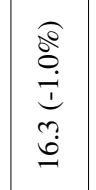 & $\begin{array}{l}\text { Q } \\
\text { in } \\
i \\
n \\
i \\
n\end{array}$ & 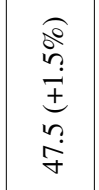 & 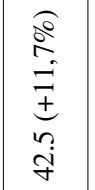 & 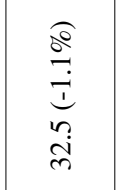 & 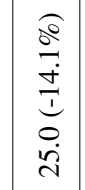 \\
\hline 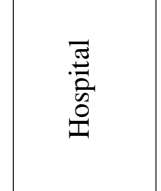 & $\Sigma$ & 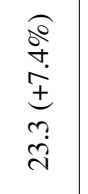 & 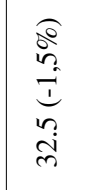 & 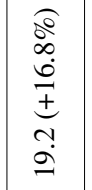 & 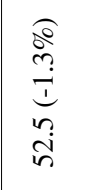 & 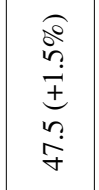 & 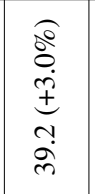 & 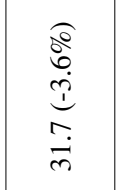 & 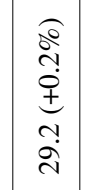 \\
\hline 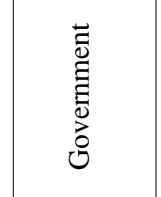 & $\Sigma$ & 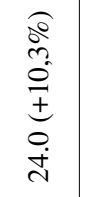 & $\begin{array}{l}\widehat{Q} \\
\infty \\
\dot{+} \\
\pm \\
0 \\
\dot{0} \\
\dot{m}\end{array}$ & 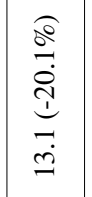 & 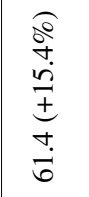 & 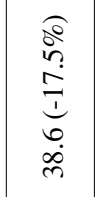 & 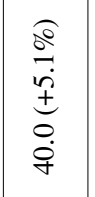 & 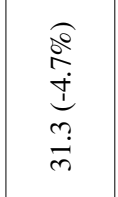 & 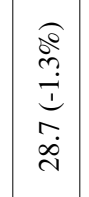 \\
\hline 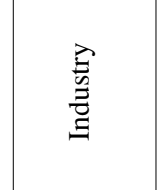 & $\Sigma$ & 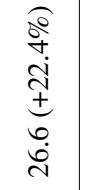 & 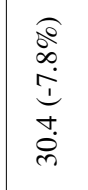 & 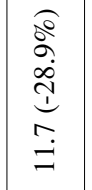 & $\begin{array}{l}0 \\
0 \\
0 \\
0 \\
+ \\
\infty \\
0 \\
0 \\
0\end{array}$ & 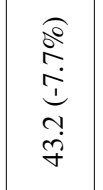 & 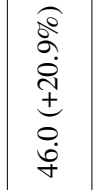 & 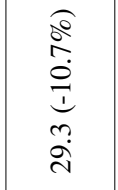 & 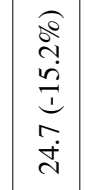 \\
\hline 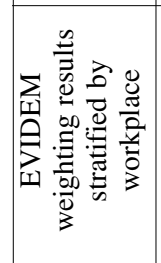 & & 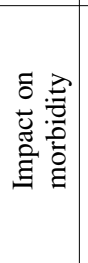 & 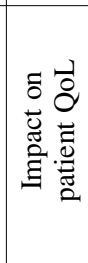 & 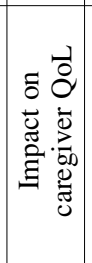 & 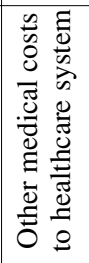 & 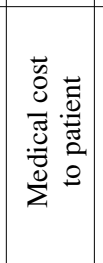 & 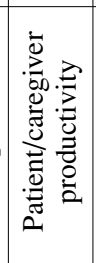 & 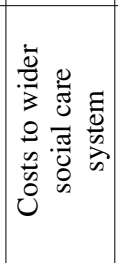 & 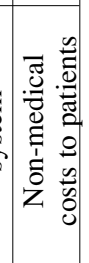 \\
\hline
\end{tabular}


rected for this imbalance, e.g. by using stakeholder group averages while calculating overall averages (e.g. independent of subgroup size). All results are presented in graphs and tables that provide a clear overview of the results, which help interpretation by the reader.

It went beyond the scope of this study to increase the number of respondents further, e.g. to even out the subgroup sizes and increase the likelihood of finding significance in the results, as this would require extensive stakeholders mapping. The number of experts with experience in the field of rare diseases and/or HTA is often limited, especially in smaller countries or those with a less developed healthcare and reimbursement system. Only a handful of patients were identified in this study and these patients showed difficulty in properly filling in the questionnaire, even during a face-to-face meeting with an expert. Eventually, the questionnaires of only 2 patient representatives could be included in the results. The results of the patient subgroup are therefore of limited validity. The authors have considered that the presented subject matter of MCDA models in rare diseases is a highly technical niche subject with medical and pharmacoeconomic elements and jargon. Given that a typical patient population will have generally seen a lower education than professionals in the industry, HTA or medical professions, this might present hurdles in understanding. For future involvement of patients or caregivers in MCDA weight elicitation, a simplified model (with simplified terminology) and experi- enced specialist representatives should be considered. Garau et al. had similar findings in their study and recommended simplified language, lay terminology and an interactive process around the weighting process in order to guarantee adequate understanding of the method, as well as a validation step with the interviewed stakeholders (35).

\section{Regarding the questionnaire methodology}

The fields containing demographic characteristics within the questionnaire allowed for some flexibility, e.g. "experience in HTA/rare diseases" could be interpreted differently by individual stakeholders. Similarly, some workplaces can be overlapping in practice which the questionnaire could not accommodate for, e.g. hospitals and (hospital) pharmacies, universities and government institutions, which may affect certain (stratification) results.

Only the current profession of respondents was taken into account; it is unknown if and how different previous professions (e.g. currently in government, previously in industry or vice-versa) would affect scores and correlations.

A larger number of data fields, greater sample size and further analysis (e.g. regression analysis) would be needed for more complete understanding. It would, however, be difficult to find representative subgroups without cross-pollination between industry, government/HTA and medical fields. Results relating to stratification with HTA and RD experience can overlap, as these are 2 areas of expertise that are likely to occur in HTA professionals.

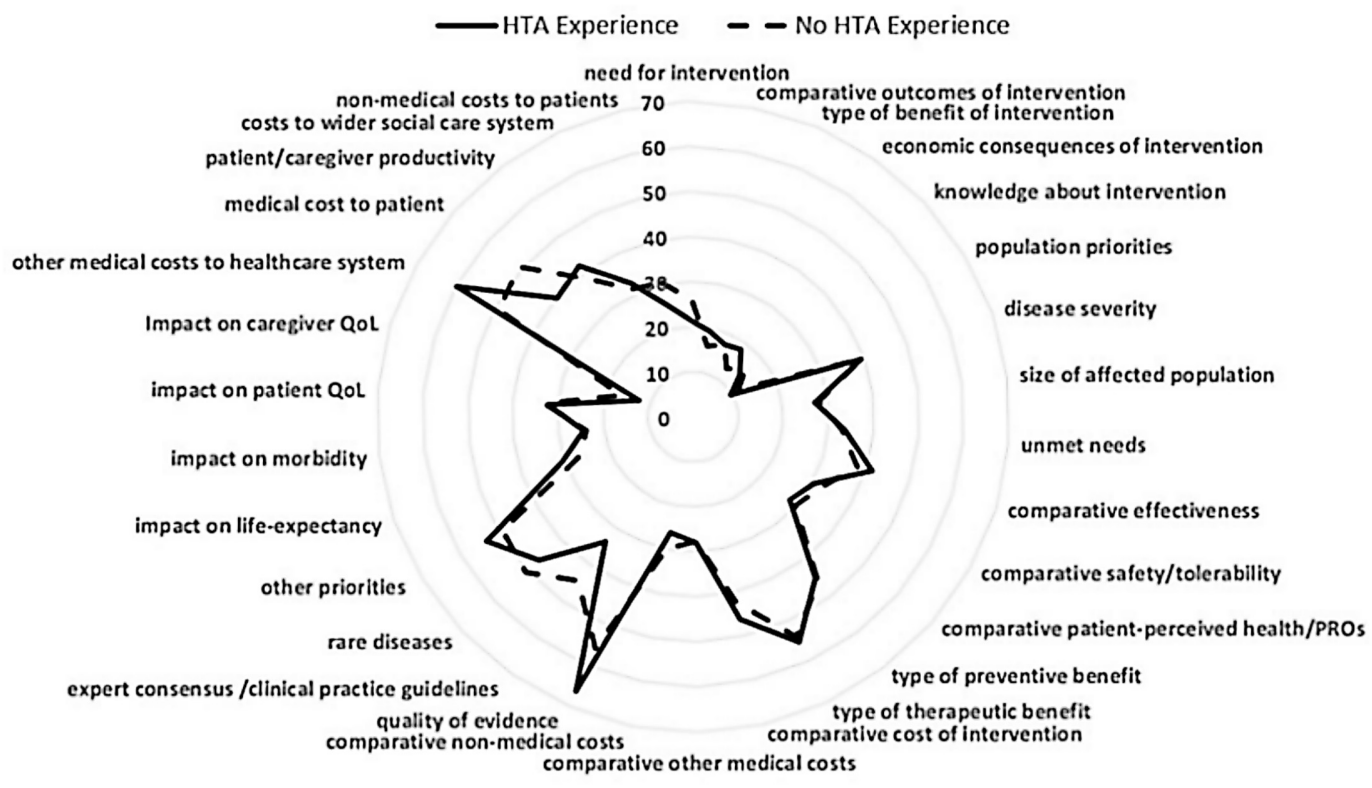

Figure 6. Weighting results of HTA vs non-HTA experienced respondents 


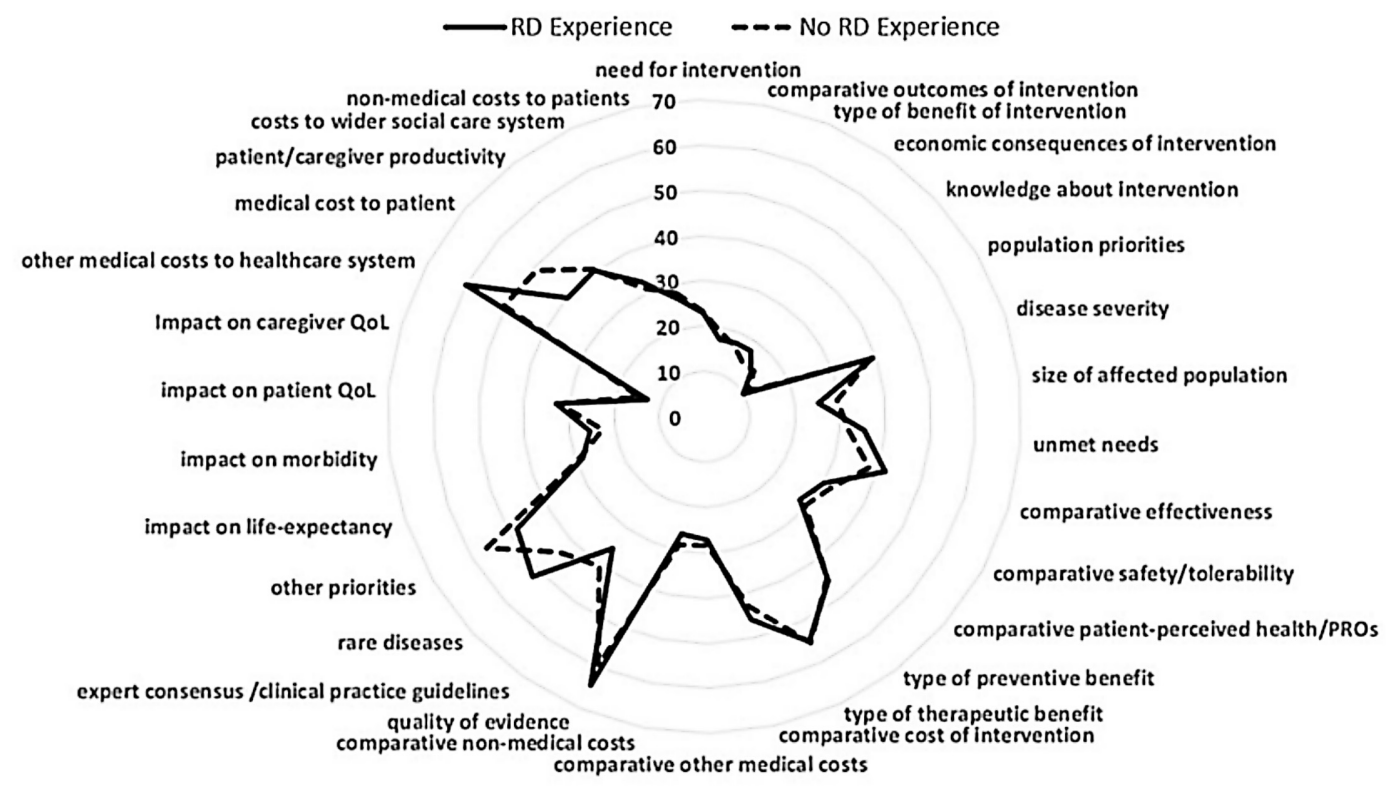

Figure 7. Weighting results of rare disease vs non-rare disease experienced respondents

Additional statistical analysis would be needed to clearly distinguish correlation and eliminate confounding.

The weighting method used in this study was hierarchical 100-point-allocation. To further verify the accuracy of the model in characterizing stakeholder weighting preferences, multiple (at least 2) weighting methods should be used and compared for verification of the consistency of the model.

Further research would preferably include model validation by testing one or more drugs for MCDA appraisal and if possible, within different healthcare systems/countries.

\section{Regarding the weighting results}

The results give an overview of current MCDA viewpoints in 7 countries. However, the external applicability of the aggregated weighting results of 7 countries that are economically and culturally different on the national level is uncertain, as it is likely that weighting scores will differ on a national basis. Factors related to economy, healthcare and reimbursement systems, in particular, are expected to show substantial variability. Countries with less developed economies or with specific healthcare resource restrictions are likely to attach more weight to certain to economic factors. Cultural differences may have an influence, e.g. on field weights attached to patient-reported outcomes (PROs) versus clinical outcomes (36). On the other hand, weights assigned to 'core' criteria related to the safety and efficacy of treatment are likely easier to extrapolate across regions. To further overcome these hurdles, an international collaboration to establish a commonly acceptable level of evidence and criteria weights in the decision models could be considered.

Model alterations and newly developed models might be expected in the future as MCDA experience grows. One point that was raised by multiple respondents is a possible overlap between several criteria and domains in the EVIDEM framework, leading to potential double-counting of criteria, e.g. effectiveness being measured in comparative effectiveness criteria as well as "Type of Benefit" (this point has been raised also by the authors of one of a recent publications (42)). Strict separation (nonduplication) of MCDA model criteria is also recommended by the ISPOR Task Force (40). In principle, the use of 'comparative' data can be questioned in the rare disease setting, as there often is no approved orphan drug (comparator) available, although 'similar' rare diseases, off-label treatments or interventions with a similar mode of action could be considered in comparison (32).

\section{Comparative analysis with other studies}

Several authors have published weighting results using the EVIDEM model (v3.0) but not with the EVIDEM model that has been adjusted for rare diseases $(24,35,36)$. The results of these 3 studies were based on a single comparative weighting procedure in which points were divided over all 12 EVIDEM criteria at once, regardless of the model structure. In contrast, this publication uses a weighting process based 
on the EVIDEM model (v3.0) and reflects the actual weighting choices in this model. The authors considered performing the weighting process in the context of the model and with the perspective of comparative choices to be more appropriate and with increased relevance of the weighting results.

Wagner et al. (36) found the following EVIDEM criteria to be the highest ranked (among all cri- teria) in France, Italy and Spain (8 stakeholders per country): Comparative effectiveness, Disease Severity, Quality of Evidence and Comparative Safety, Type of Preventive Benefit. Other criteria were more varied between countries, but Comparative Other Costs, PRO's and Expert Consensus/CPG's were generally scored low. Gillabert-Perramon et al. (24) found Disease Severity, Unmet Needs,

Table 3. Overall EVIDEM weighting results stratified by Experience in HTA and Experience in Rare Diseases.

\begin{tabular}{|c|c|c|c|c|c|}
\hline Experience in HTA / Experience & \multicolumn{2}{|c|}{ HTA Experience } & \multicolumn{2}{|c|}{ Rare Disease Experience } & \multirow{2}{*}{$\begin{array}{l}\text { Expected } \\
\text { average } \\
\text { field score }\end{array}$} \\
\hline EVIDEM FIELD & Yes & No & Yes & No & \\
\hline Need for intervention & $21.3( \pm 10.1)$ & $26.1( \pm 15.1)$ & $23.0( \pm 9.9)$ & $23.2( \pm 14.7)$ & \multirow{6}{*}{16.67} \\
\hline Comparative outcomes of intervention & $19.3( \pm 10.9)$ & $15.9( \pm 15.1)$ & $17.3( \pm 9.6)$ & $19.0( \pm 9.7)$ & \\
\hline Type of benefit of intervention & $17.5( \pm 10.9)$ & $17.6( \pm 15.1)$ & $17.8( \pm 9.7)$ & $17.1( \pm 11.1)$ & \\
\hline Economic consequences of intervention & $18.2( \pm 10.6)$ & $13.0( \pm 15.1)$ & $17.6( \pm 11.3)$ & $14.5( \pm 8.9)$ & \\
\hline Knowledge about intervention & $13.9( \pm 7.5)$ & $15.5( \pm 15.1)$ & $14.2( \pm 7.4)$ & $14.9( \pm 7.6)$ & \\
\hline Population priorities & $9.8( \pm 6.5)$ & $11.8( \pm 15.1)$ & $10.0( \pm 7.0)$ & $11.2( \pm 6.3)$ & \\
\hline Disease severity & $39.2( \pm 17.0)$ & $39.1( \pm 15.1)$ & $39.3( \pm 16.3)$ & $38.6( \pm 16.4)$ & \multirow{3}{*}{33.33} \\
\hline Size of affected population & $27.0( \pm 15.0)$ & $27.9( \pm 13.8)$ & $25.3( \pm 14.4)$ & $29.5( \pm 14.3)$ & \\
\hline Unmet needs & $33.8( \pm 14.0)$ & $33.0( \pm 13.9)$ & $35.4( \pm 13.8)$ & $31.9( \pm 13.7)$ & \\
\hline Comparative effectiveness & $41.4( \pm 13.9)$ & $37.9( \pm 12.0)$ & $41.8( \pm 14.3)$ & $38.1( \pm 11.9)$ & \multirow{3}{*}{33.33} \\
\hline Comparative safety/tolerability & $30.4( \pm 10.5)$ & $32.2( \pm 9.8)$ & $30.1( \pm 9.5)$ & $32.2( \pm 11.1)$ & \\
\hline Comparative patient-perceived health/pros & $28.2( \pm 15.7)$ & $29.9( \pm 12.5)$ & $28.1( \pm 13.6)$ & $29.7( \pm 15.8)$ & \\
\hline Type of preventive benefit & $44.7( \pm 16.7)$ & $46.0( \pm 12.6)$ & $45.4( \pm 16.6)$ & $44.8( \pm 13.7)$ & \multirow{2}{*}{50} \\
\hline Type of therapeutic benefit & $55.3( \pm 16.7)$ & $54.0( \pm 12.6)$ & $54.6( \pm 16.6)$ & $55.2( \pm 13.7)$ & \\
\hline $\begin{array}{l}\text { Comparative cost-consequences - cost of } \\
\text { intervention }\end{array}$ & $46.0( \pm 18.3)$ & $42.3( \pm 13.9)$ & $46.1( \pm 17.4)$ & $42.9( \pm 16.3)$ & \multirow{3}{*}{33.33} \\
\hline $\begin{array}{l}\text { Comparative cost consequences -other } \\
\text { medical costs }\end{array}$ & $27.9( \pm 13.3)$ & $27.8( \pm 8.7)$ & $27.4( \pm 10.5)$ & $28.4( \pm 13.1)$ & \\
\hline $\begin{array}{l}\text { Comparative cost consequences- } \\
\text { non-medical costs }\end{array}$ & $26.1( \pm 14.0)$ & $29.9( \pm 11.9)$ & $26.5( \pm 12.6)$ & $28.7( \pm 14.2)$ & \\
\hline Quality of evidence & $66.1( \pm 17.8)$ & $55.7( \pm 12.5)$ & $64.4( \pm 17.0)$ & $59.7( \pm 16.3)$ & \multirow{2}{*}{50} \\
\hline Expert consensus /clinical practice guidelines & $33.9( \pm 17.8)$ & $44.3( \pm 12.5)$ & $35.6( \pm 17.0)$ & $40.3( \pm 16.3)$ & \\
\hline Rare diseases & $46.6( \pm 24.9)$ & $50.8( \pm 22.4)$ & $51.8( \pm 22.8)$ & $43.8( \pm 24.8)$ & \multirow{2}{*}{50} \\
\hline Other priorities & $53.4( \pm 24.9)$ & $49.2( \pm 22.4)$ & $48.2( \pm 22.8)$ & $56.2( \pm 24.8)$ & \\
\hline Impact on life-expectancy & $30.6( \pm 13.0)$ & $26.4( \pm 10.5)$ & $28.5( \pm 12.7)$ & $29.7( \pm 11.8)$ & \multirow{4}{*}{25} \\
\hline Impact on morbidity & $24.6( \pm 10.2)$ & $23.8( \pm 9.8)$ & $25.5( \pm 10.1)$ & $22.9( \pm 9.8)$ & \\
\hline Impact on patient QoL & $32.2( \pm 10.8)$ & $33.1( \pm 8.3)$ & $32.9( \pm 10.7)$ & $32.3( \pm 8.8)$ & \\
\hline Impact on caregiver QoL & $12.5( \pm 9.4)$ & $16.7( \pm 10.2)$ & $13.1( \pm 9.5)$ & $15.1( \pm 10.3)$ & \\
\hline Other medical costs to healthcare system & $59.9( \pm 22.2)$ & $49.1( \pm 20.2)$ & $60.1( \pm 23.3)$ & $50.8( \pm 19.5)$ & \multirow{2}{*}{50} \\
\hline Medical cost to patient & $40.1( \pm 22.2)$ & $50.9( \pm 20.2)$ & $39.9( \pm 23.3)$ & $49.2( \pm 19.5)$ & \\
\hline Patient/caregiver productivity & $41.9( \pm 19.2)$ & $38.3( \pm 15.6)$ & $40.4( \pm 18.3)$ & $40.8( \pm 17.7)$ & \multirow{3}{*}{33.33} \\
\hline Costs to wider social care system & $32.6( \pm 15.9)$ & $31.3( \pm 11.8)$ & $32.9( \pm 14.9)$ & $31.2( \pm 14.0)$ & \\
\hline Non-medical costs to patients & $25.5( \pm 11.2)$ & $30.4( \pm 13.6)$ & $26.7( \pm 11.6)$ & $28.0( \pm 13.2)$ & \\
\hline
\end{tabular}


Comparative Effectiveness to be highest rated in one overall criteria weighting exercise with 16 stakeholders. Population Size and Comparative Other and NonMedical Costs were rated lowest. Garau et al. found Disease Severity, Comparative Effectiveness and Type of Therapeutic Benefit to be rated highest by 2 stakeholder groups (Patients and Clinicians) and economic factors the lowest, whereas the subgroup of Payers found Unmet Needs, Quality of Evidence and Cost of Intervention the most important (35).

Even though the highest rated criteria are similar across studies, the results of these 4 studies show that even with similar methodology, weighting scores differ considerably for the majority of criteria, between stakeholders and countries. Due to the different methods used between this study and the previous studies, an in-depth comparison was viewed to be of limited relevance. A standardized weighting approach that takes into account stakeholder selection choices, weighting method(s) and general context would be beneficial to increase comparability and transferability of weighting results. To reduce variability the authors recommend that future MCDA weighting research, and actual HTA weighting processes for that matter, consider model design factors in order to generate relevant and meaningful results.

\section{CONCLUSIONS}

Despite a generally accepted view on which criteria MCDA models for rare diseases should try to capture, i.e. characteristics beyond traditional cost and benefit, there is still discussion on the fundamental methodological and mathematical aspects of the models. In addition, hurdles exist in the practical implementation of MCDA into national law and guidelines. Uptake by HTA bodies is still sparse and harmonization of MCDA models seems to be necessary. The results of several pilot studies and stakeholder interviews show that a simplification of MCDA models like EVIDEM would be beneficial, especially to improve clarity and score interpretation. Weight elicitation is an essential step in the design and implementation of MCDA and similar decision-making models. This study has presented weighting scores for the EVIDEM 3.0 MCDA model for rare diseases and has highlighted differences and similarities between the weighting by a range of stakeholders and across regions, and as such, this study could serve to inform decision makers. The results should give an indication of current thinking in MCDA and aid in predicting weights and preferences given to model criteria, and therefore also MCDA outcomes. Moreover, the presented data can be used by researchers in future stud- ies or combined with data from other sources to increase validity, either with the EVIDEM framework or other comparable MCDA models. Larger data sets could help the adaptation and the implementation of EVIDEM 3.0 or similar models into practice.

Further research, sharing of experiences and multi-stakeholder discussion is necessary with a broad range of stakeholders, e.g. payers, patients, medical professionals and industry, in order to review and align MCDA research and define a path forward for a robust and sustainable improvement of this promising methodology in HTA and its application in the rare disease arena.

\section{Conflict of interests}

This research received no grant from any funding agency in the public, commercial, or not-forprofit sectors and authors declare that we have no competing interests.

\section{Acknowledgements}

The authors would like to thank Maryze Schoneveld-Van der Liude for her contributions which were invaluable to this publication.

\section{REFERENCES}

1. http://www.ema.europa.eu/ema/index.jsp?curl= pages/regulation/general/general content 000029. jsp\&mid=WC0b01ac0580b18a41 (accessed on 03.11.2018).

2. http://www.ema.europa.eu/docs/en GB/document library/Leaflet/2017/12/WC500240710. pdf (accessed on 03.11.2018).

3. European Commission: Rare Diseases - A major unmet medical need, Research \& Innovation Projects for Policy, 2017 https://ec.europa.eu/ info/sites/ info/files/research and innovation/p4p/documents/p4p infographic-rarediseases.pdf (accessed on 03.11.2018).

4. https://www.rarediseaseday.org/article/themeof-the-year-living-with-a-rare-disease (accessed on 03.11.2018).

5. Jakovljevic M., Lazarevic M., Milovanovic O., Kanjevac T.: Front. Pharmacol. 7, 18 (2016).

6. Pejcic A.V., Iskrov G., Jakovljevic M., Stefanov R.: Health Policy 122, 583 (2018).

7. Simoens S.: Orphanet J. Rare Dis. 6, 42 (2011).

8. Morel T., Cano S.J.: Orphanet J. Rare Dis. 12, 171 (2017).

9. Picavet E., Cassiman D., Simoens S.: J. Clin. Pharm. Ther. 40, 304 (2015). 
10. Drummond M.F.: Eurohealth 14, 16 (2008). Available online at: http://apps.who.int/medicinedocs/documents/s20976en/s20976en.pdf (accessed on 03.11.2018).

11. 5. U.S. Food and Drug Administration, Pariser A. Rare Disease and Clinical Trials (04.11.2014) https://www.fda.gov/downloads/ Drugs/NewsEvents/UCM440797.pdf (accessed on 03.11.2018).

12. Hilgers R.D., König F., Molenberghs G., Senn S.: J. Rare Dis. Res. Treat. 1, 53 (2016).

13. Czech M., Baran-Kooiker A., Holownia M., Kooiker C., Sykut-Cegielska J.: Acta Pol. Pharm. 75, 1409 (2018).

14. Simoens S.: Expert Rev. Pharmacoecon. Outcomes Res. 14, 315 (2014).

15. Libura M., Władysiuk M., Małowicka M., Grabowska E., Gałązka-Sobotka M., Gryglewicz J.: Rare disease in Poland, current status and perspectives; Book, ISBN 978-83-64054-73-0, Uczelnia Łazarskiego (2016).

16. Belgin G., Macarthur D.: Access to Orphan Drugs in Turkey, Jan 04, 2016 http://www. pharmexec.com/access-orphan-drugs-turkey (accessed on 03.11.2018).

17. Kılıç P., Koçkaya G., Yemşen Ö., Tan C., Handan Öztunca F. et al.: JPHSR 4, 151 (2013).

18. https://www.nice.org.uk/about/what-wedo/our-programmes/nice-guidance/nice-technology-appraisal-guidance/consultation-onchanges-to-technology-appraisals-and-highlyspecialised-technologies (accessed on 03.11. 2018).

19. Paulden M.: Expert Rev. Pharmacoeconomics Outcomes Res. 17, 239 (2017)

20. Weinstein N., Martin M., Campbell R.: PHP48, Value in Health, October-November, 20, A660 (2017).

21. Thokala P., Devlin N., Marsh K., Baltussen R., Boysen M. et al.: Value Health 19, 1 (2016).

22. Marsh K., Goetghebeur M., Thokala P., Baltussen R.: Multi-Criteria Decision Analysis to Support Healthcare Decisions, ISBN 978-3319-47540-0, Springer International Publishing AG 2017.

23. Schey C., Krabbe P.F.M., Postma M.J., Connolly M.P.: Orphanet J. Rare Dis. 12, 10 (2017).

24. Gilabert-Perramon A., Torrent-Farnell J., Catalan A., Prat A., Fontanet M. et al.: International Journal of Technology Assessment in Health Care, 33:1 (2017).

25. European Commission: Finn Børlum Kristensen: Mapping of HTA methodologies in EU and
Norway (June 2017) https://ec.europa. eu/ health/sites/health/files/technology assessment/docs/2018 mapping methodologies en.pdf (accessed on 03.11.2018).

26. Endrei D., Molics B., Ágoston I.: Value Health 17, 307 (2014).

27. Radaelli G., Lettieri E., Masella C., Merlino L., Strada A., Tringali M.: Int. J. Technol. Assess. Health Care 30, 105 (2014).

28. Kolasa K., Zwolinski K.M., Kalo Z., Hermanowski T.: Orphanet J. Rare Dis. 11, 23 (2016)

29. Iskrov G., Miteva-Katrandzhieva T., Stefanov R.: Front. Public Health 4, 214 (2016).

30. Trip A.M., Tsiachristas A., Koenders J.M., Kanters T.A.: PSY 114, Value Health 17, A323 (2014).

31. Sussex J., Rollet P., Garau M, Schmitt C., Kent A., Hutchings A.: Value Health 16, 1163 (2013)

32. Baran-Kooiker A., Czech M., Kooiker C.: Front. Public Health 6, 287( 2018).

33. Hughes-Wilson W., MoCA Concept and Pilot Project, Feedback from the process around the first pilot project, ECRD Berlin (10.05.2014) http://download.eurordis.org.s3.amazonaws.co m/moca/presentations/PRES-2014-05\%20Mo CA\%20Concept $\% 20$ and $\% 20$ Pilot $\% 20$ Project $\%$ 20(Hughes-Wilson).pdf (accessed on 03.11.2018).

34. Hughes-Wilson W., Palma A., Schuurman A., Simoens S.: Orphanet J. Rare Dis. 7, 74 (2012).

35. Garau M., Marsden G., Devlin N., Amedeo Mazzanti N., Profico A.: Office of Health Economics Research, Research Paper 16/08, December 2016 Available at: https://www.ohe. org/publications/applying-multi-criteria-decision-analysis-mcda-approach-elicit-stakeholders\%E2\%80\%99 (accessed on 03.11.2018).

36. Wagner M., Khoury H., Bennetts L., Berto P., Ehreth J., Badia X., Wagner M.: BMC Cancer 17, 272 (2017).

37. https://www.evidem.org/(accessed on 03.11.2018).

38. Goetghebeur M.M., Wagner M., Khoury H., Levitt R.J., Erickson L.J., Rindress D.: BMC Health Services Research 8:270 44 (2008).

39. Wagner M., Khoury H., Willet J., Rindress D., Goetghebeur M.: PharmacoEconomics 34, 285 (2016).

40. Marsh K., IJzerman M., Thokala P., Baltussen R., Boysen M. et al.: Value Health 19, 125 (2016).

41. Thokala P., Duenas A. (2012).: Value Health, 15, 1172 (2012).

42. Marsh K.D., Sculpher M., Caro J.J., Tervonen T.: Value Health, 21, 394 (2018).

Received: 1.12.2018. 